\title{
Diversidade de estilos estruturais e processos de deformação em depósitos de transporte em massa
}

\author{
Diversity of structural styles and deformation processes in mass-transport deposits
}

\author{
MÉROLYN CAMILA NAVES DE LIMA RODRIGUES ${ }^{1}$, BARBARA TRZASKOS², \\ FERNANDO FARIAS VESELY ${ }^{3} \&$ THAMMY ELLIN MOTTIN ${ }^{4}$
}

\author{
${ }^{1}$ Universidade Federal do Paraná (UFPR), Curitiba, Paraná, Brasil, https://orcid.org/0000-0003-2513-7276, merolyn.rodrigues@ufpr.br \\ ${ }^{2}$ Universidade Federal do Paraná (UFPR), Curitiba, Paraná, Brasil, barbaratrzaskos@ufpr.br \\ ${ }^{3}$ Universidade Federal do Paraná (UFPR), Curitiba, Paraná, Brasil, vesely@ufpr.br \\ ${ }^{4}$ Universidade Federal do Paraná (UFPR), Curitiba, Paraná, Brasil, thammymottin@gmail.com
}

\begin{abstract}
Resumo
Depósitos de transporte em massa (mass-transport deposits - MTDs) resultam de importantes processos de remobilização gravitacional e ressedimentação em ambiente subaquático. Esses depósitos são recorrentes ao longo da seção estratigráfica do Grupo Itararé, na Bacia do Paraná. Portanto, são considerados importantes elementos deposicionais para compreender a evolução tectonoestratigráfica da bacia durante a deposição dessa unidade estratigráfica. A deformação é uma característica importante desses depósitos e resulta do transporte talude abaixo de sedimentos pouco ou não-litificados. Os MTDs do Grupo Itararé apresentam diferentes estruturas, tais como dobras, falhas, boudins, feições de cisalhamento, injetitos, entre outras. O estudo dessas estruturas pode fornecer informações importantes sobre evolução desses depósitos e a sua relação com os demais depósitos que compõem o Grupo Itararé. Além disso, a compreensão da anisotropia desses depósitos pode auxiliar em estudos sobre seu impacto em sistemas petrolíferos. No presente artigo, as estruturas descritas em MTDs do Grupo Itararé foram agrupadas em quatro diferentes estilos estruturais de deformação, que incluem: compressivo, distensivo, cisalhante e de liquefação/fluidificação/injeção. A diversidade de estilos estruturais parece resultar de diferentes fatores associados a relação espacial e temporal de formação das estruturas, incluindo mudanças de reologia.
\end{abstract}

Palavras-chave: deformação penecontemporânea, sedimentos inconsolidados, fluxo gravitacional em massa, Grupo Itararé, estruturas de deformação de sedimentos

\begin{abstract}
Mass-transport deposits (MTDs) result from important processes of downslope remobilization and resedimentation in subaquatic settings. These deposits are recurrent across the stratigraphic succession of the Itararé Group in the Paraná Basin. Therefore, they are considered important depositional elements to comprehend the tectono-stratigraphic evolution of the basin during the Permocarboniferous. Deformation is an important characteristic of these deposits and results from downslope flowage of non- to poorly-lithified sediments. MTDs of the Itararé Group show different structures, such as folds, faults, boudins, shear features, injectites, and others. The study of such structures can provide important information about the evolution of these deposits and other genetically-related deposits of the Itararé Group. Besides, the understanding of MTDs anisotropy can help in studies about their role as reservoirs or seals in petroleum exploration. In the present paper, the structures identified in MTDs of the Itararé Group are classified in four different structural styles: compressional, extensional, shearing and liquefaction/fluidization/injection. The diversity of structural styles seems to result from several factors associated with the spatial and temporal relationships of structure development, including changes in rheology.
\end{abstract}

Keywords: penecontemporaneous deformation, uncosolidated sediments, mass-gratitational flow, Itararé Group, soft-sediment deformation structures 


\section{Introdução}

Sedimentos remobilizados por fluxo gravitacional em massa compreendem importantes elementos deposicionais em ambientes marinhos e os depósitos resultantes compõem parcela importante do registro geológico marinho profundo antigo e moderno (e.g., Martinsen 1989, 1994, Posamentier \& Walker 2006). Os fluxos gravitacionais são ainda importantes na evolução das margens continentais mundiais, modificando e definindo a morfologia submarina ao longo de linhas de costas, taludes e em bacias de águas profundas (e.g., De Blasio \& Elverhøi 2010, Moscardelli et al. 2006). Portanto, tais fluxos podem impactar na exploração de petróleo, uma vez que podem pré-condicionar a geometria de reservatórios ou agir como selos (Armitage et al. 2009).

Fluxos gravitacionais coesivos geram depósitos de transporte em massa (em inglês mass-transport deposits $M T D s$ ) a partir de um ou mais processos tais como deslizamentos, escorregamentos e fluxos de detritos (Nardin et al. 1979, Nemec 1990, Martinsen 1994, Dasgupta 2003, Jenner et al. 2007, Posamentier \& Martinsen 2011). Esses processos ocorrem ao longo de taludes ou gradientes, desde menos de $0,1^{\circ}$ de inclinação, tais como a frente de deltas modernos (e.g., Nardin et al. 1979, Prior \& Colemam 1978, Martinsen 1994, Jenner et al. 2007), e podem ser desencadeados por instabilidades geradas por diversos fatores sedimentares (como incremento do ângulo do talude devido a rápida sedimentação) e tectônicos (como eventos sísmicos; e.g. Martinsen 1994).

As características dos MTDs tendem a ser extremamente variáveis em relação a geometria, morfologia, dimensão, composição, estruturas e fácies (e.g., Posamentier \& Kolla 2003, De Blasio \& Elverhøi 2010). Com relação à deformação, esses depósitos mostram complexo registro estrutural com diversidade de estruturas, que resulta da relação entre instabilidades associadas com o gradiente de taludes, a topografia, reologia e padrões de fluxo (Jones 1939, Hansen 1971, Woodcock 1979, Farrell 1984, Martinsen 1989, Strachan \& Alsop 2006).

No Grupo Itararé, unidade permocarbonífera da Bacia do Paraná, os MTDs são recorrentes e diversas estruturas de deformação têm sido documentadas (e.g., Rocha-Campos 1963; Salamuni et al. 1966, Eyles et al. 1993, Vesely et al. 2005, Carneiro \& Costa 2006, Vesely \& Assine 2006, Suss et al. 2014, Carvalho \& Vesely 2017, Valdez-Buso et al. 2019, Mottin et al. 2018, Vesely et al. 2018, Schemiko et al. 2019, Rodrigues et al. 2020). Contudo, não há ainda estudo sistemático de caracterização dessas estruturas. O objetivo do presente artigo é ilustrar e caracterizar a diversidade de estilos estruturais associados aos MTDs, com base em diferentes estruturas documentadas em afloramentos do Grupo Itararé na borda leste da Bacia do Paraná entre os estados do Paraná e Santa Catarina (Fig. 1A).

\section{Registro de deformações penecontemporâneas e MTDs no Grupo Itararé}

Desde os primeiros estudos na Bacia do Paraná, depósitos permocarboníferos com evidências de influência glacial têm sido descritos (e.g., Derby 1878, White 1908, Oliveira 1916, 1927, Leinz 1937, Gordon Jr. 1947,
Almeida 1948). Por muitos anos, pesquisadores interpretaram grande parte dos depósitos do Grupo Itararé como resultantes de deposição em ambiente glacio-terrestre, assim como as feições de deformação penecontemporânea foram interpretadas como oriundas de glaciotectônica (e.g., Leinz 1937, Almeida 1948, Martin 1961, Canuto 1985).

Contudo, estudos sedimentológicos e paleontológicos a partir da metade do século 20 passaram a indicar a influência marinha importante na deposição do Grupo Itararé (e.g., Sanford \& Lange 1960, Salamuni et al. 1966, Schneider et al. 1974, França \& Potter 1988, Castro 1991, Gama Jr. et al. 1992, Souza \& Marques-Toigo 2003, Vesely \& Assine 2004, 2006, d'Avila 2009). Durante toda a deposição, os fluxos gravitacionais subaquosos foram recorrentes (Vesely et al. 2018) e depósitos de transporte em massa, bem como estruturas deformacionais associadas têm sido documentados ao longo de toda a sucessão estratigráfica (e.g., Rocha-Campos 1963, Salamuni et al. 1966, Gama Jr. et al. 1992, Eyles et al. 1993, Vesely et al. 2005, Carneiro \& Costa 2006, Vesely \& Assine 2006, Suss et al. 2014, Carvalho \& Vesely 2017, Mottin et al. 2018, Vesely et al. 2018, Schemiko et al. 2019, Rodrigues et al. 2020).

Nos últimos anos, vários estudos têm abordado diversos aspectos dos MTDs do Grupo Itararé, tais como a geometria deposicional, relações de contato e potencialidade econômicas desses depósitos, fácies, modelo deposicional, características deformacionais, entre outros (e.g., Suss et al. 2014, Carvalho \& Vesely 2017, Valdez-Buso et al. 2019, Mottin et al. 2018, Vesely et al. 2018, Schemiko et al. 2019, Rodrigues et al. 2020).

\section{Aspectos gerais dos MTDs no Grupo Itararé}

No Grupo Itararé, os MTDs documentados correspondem a 1) blocos alóctones (clastos intrabacinais) de arenitos e ritmitos (Fig. 1B), 2) arenitos, ritmitos e folhelhos deformados (e.g., Fig. 2A, 3A e 7A), e 3) diamictitos areno-argilosos (e.g., Fig. 3B, 6A e 8B) heterogêneos (matriz bandada) a homogêneos (matriz maciça) contendo grânulos a blocos intra- (arenito, folhelho, ritmito, e fragmentos de plantas) e extrabacinais (granitos e rochas metemórficas), alguns dos quais estriados e facetados (e.g., Vesely \& Assine 2006, Suss et al. 2014, Carvalho \& Vesely 2017, Valdez-Buso et al. 2019, Mottin et al. 2018, Vesely et al. 2018, Schemiko et al. 2019, Rodrigues et al. 2020).

As dimensões e limites de um único MTD são, comumente, difíceis de definir e avaliar devido ao limitado grau de exposição do Grupo Itararé. Geralmente, a espessura dos MTDs varia de cerca de $5 \mathrm{~m}$ a dezenas de metros (Carvalho \& Vesely 2017, Mottin et al. 2018, Schemiko et al. 2019). A base dos MTDs é comumente erosiva e irregular. Quando identificado, o limite do topo dos MTDs é, geralmente, plano, mas relevo de baixa amplitude foi documentado localmente, o que condiciona a deposição das fácies subsequentes (Rodrigues et al. 2020).

As diferentes estruturas deformacionais em MTDs do Grupo Itararé, tais como dobras, falhas, boudins, basculamento de camadas e grandes blocos, entre outras, ocorrem dentro dos limites dos depósitos e são interpretadas como resultantes de eventos de fluxo em massa ao invés 


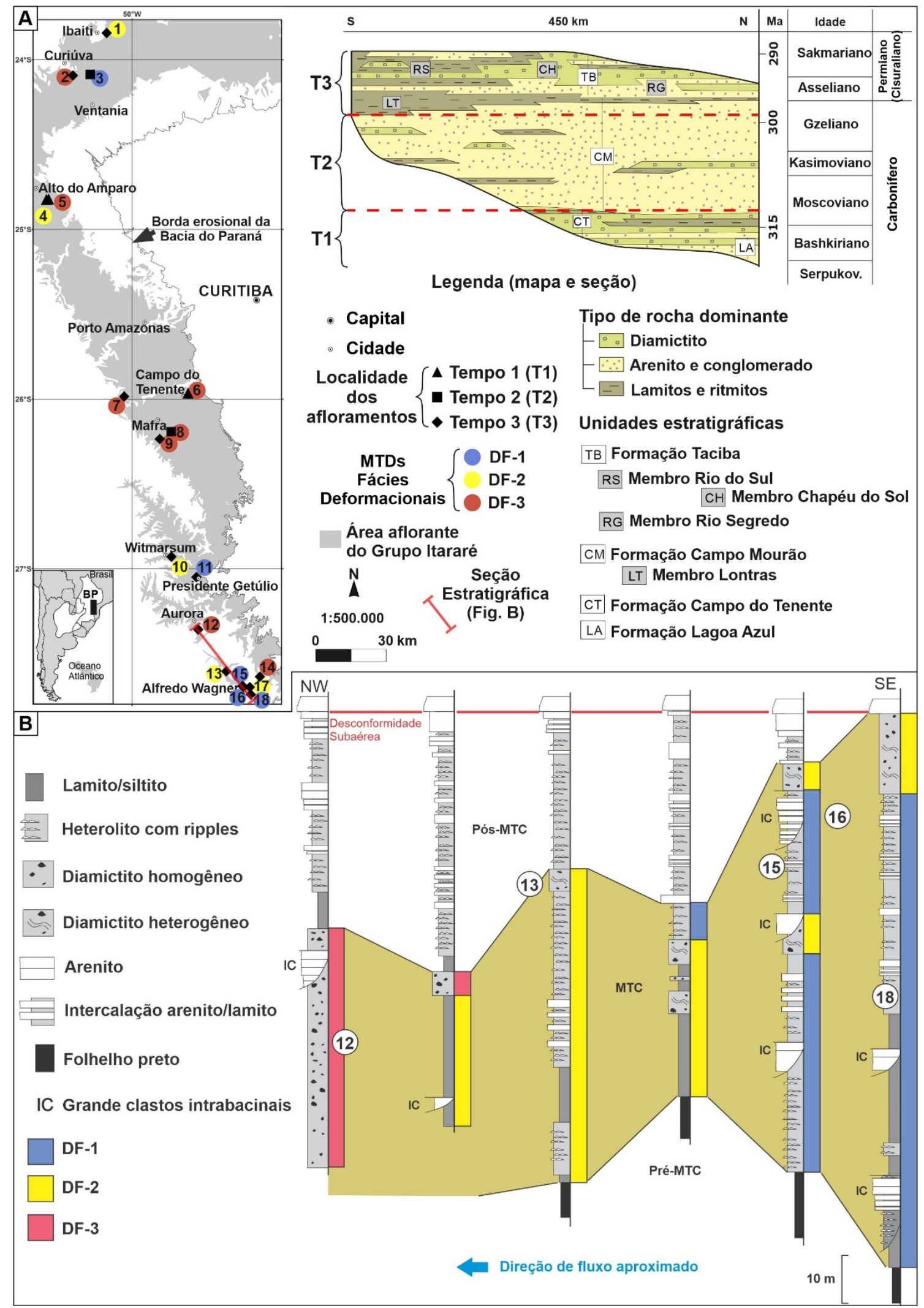

Figura 1 -A) Mapa e contexto estratigráfico da área de estudo na borda leste da Bacia do Paraná, com indicação da posição geográfica e estratigráfica, e fácies deformacionais dos MTDs (localidade dos afloramentos). Afloramentos de 1 a 7 são localizadas no estado do Paraná e afloramentos 8 a 18 se localizam no estado de Santa Catarina. B) Seção estratigráfica (extensão de cerca de 50 km; sem escala horizontal; localização indicada no mapa) que mostra a porção superior da Formação Taciba na região sul da área, com indicação do MTC, distribuição vertical das fácies deformacionais (DF-1, DF-2 e DF-3) e localização aproximada de localidade estudadas (números circundados). Mapa e seção estratigráfica traduzidos e adaptados de Rodrigues et al. (2020). Nomenclatura litoestratigráfica de acordo com França \& Potter (1988) e Vesely et al. (2021; neste volume). 


\begin{tabular}{llc}
\hline $\begin{array}{c}\text { Fácies deformacional } \\
\text { (tipo de MTD) }\end{array}$ & \multicolumn{1}{c}{ Características } & Matriz (\%) \\
\hline DF-1 (MTD incipiente) & $\begin{array}{l}\text { Ausência de matriz, acamamento e estruturas sedimentares } \\
\text { primárias bem preservadas. Estruturas deformacionais incluem } \\
\text { dobras (suaves a cerradas) e falhas (normais e inversas), e por } \\
\text { vezes, boudins simétricos ao longo de flancos de dobras. }\end{array}$ & 0 \\
\hline & $\begin{array}{l}\text { Matriz bandada ou homogênea, a qual ocorre como acumulações } \\
\text { nas proximidades ou entre clastos intrabacinais. Estruturas de } \\
\text { deformação incluem dobras (abertas a cerradas), falhas (normais }\end{array}$ & $<5-50$ \\
DF-2 (MTD maduro) & $\begin{array}{l}\text { inversas), boudins (simétricos ou assimétricos, feições de } \\
\text { cisalhamento (como estruturas tipo em quadrante) e injetitos } \\
\text { (injeções de areia). }\end{array}$ & \\
\hline & $\begin{array}{l}\text { Diamictito heterogêneo, com clastos intrabacinais rompidos e } \\
\text { altamente deformados com acamamento parcialmente preservado, }\end{array}$ & \\
a diamictitos quase homogêneos. Matriz é bandada ou maciça. \\
Acamamento remanescente ou matriz bandada registram \\
estruturas de deformação como dobras, falhas, boudins e outras \\
feições de cisalhamento. Outros registros de deformação incluem: \\
clastos intra- e extrabacinais orientados; cisalhamento e sulcos/ \\
estrias que deformam bordas de clastos intrabacinais; e injetitos. \\
Clastos intrabacinais deformados podem mostrar, internamente, \\
dobras, falhas, boudins e outras feições de cisalhamento anteriores \\
à ruptura.
\end{tabular}

Tabela 1 - Fácies deformacionais de MTDs definidas por Rodrigues et al. (2020).

de eventos tectônicos regionais (e.g., Vesely \& Assine 2006, Suss et al. 2014, Carvalho \& Vesely 2017, Valdez-Buso et al. 2019, Mottin et al. 2018, Vesely et al. 2018, Schemiko et al. 2019, Rodrigues et al. 2020). Diferentemente, a deformação tectônica pós-deposicional é caracterizada por fraturas subverticais que cortam múltiplas camadas e é associada a grandes zonas de falhas (e.g., Rostirolla et al. 2003, Trzaskos et al. 2006).

Em pesquisa realizada entre os estados do Paraná e Santa Catarina, Rodrigues et al. (2020) estudaram MTDs que ocorrem em três amplos intervalos de tempo do Grupo Itararé (Fig. 1A), referidos pelos autores como T1 (início do Pennsylvaniano), T2 (final do Pennsylvaniano) e T3 (início do Cisulariano), os quais se correlacionam com 3 palinozonas definidas por Souza (2006) e correspondem a formações previamente definidas (Fig. 1A; Schneider et al.1974, França \& Potter 1991). Esses MTDs foram classificados em três principais fácies deformacionais (DF-1 - incipiente; DF-2 - maduro; e DF-3 - evoluído; Tab. 1), as quais indicam diferentes graus e estágio de desagregação e mistura de sedimentos durante fluxo em massa. A definição das fácies deformacionais foi baseada na proporção relativa de clastos intrabacinais coerentes e matriz, e na relação entre as diferentes estruturas descritas (ver Rodrigues et al. 2020 para detalhes dessa classificação). Tais fácies deformacionais mostram similaridade com as fácies de $M T D$ definidas por Ogata et al. (2012), onde DF-1 mostra correspondência com slide/slump facies, DF-2 consiste numa transição entre slide/slump e blocky-flow facies, e DF-3 é uma transição entre blocky-flow e debris-flow facies segundo a classificação daqueles autores.

Na região leste de Santa Catarina, vários MTDs relativamente próximos e com boa exposição foram associados em um complexo de transporte em massa (MTC - mass- transport complex, sensu Ogata et al., 2014b; Rodrigues et al. 2020) com base em levantamentos estratigráficos (Schemiko et al. 2019; Fig. 1B). Esse MTC faz parte da porção superior do Membro Rio do Sul (Formação Taciba), o qual tem sido interpretado como um complexo deltaico progradacional com área fonte a leste (e.g. Schemiko et al. 2019). Os três tipos de fácies deformacionais foram identificados neste MTC, o que sugere que diferentes graus de homogeneização dos sedimentos, associado a uma variedade de processos de deformação, possivelmente atuaram durante a formação do complexo por um ou mais eventos de fluxo em massa (Rodrigues et al. 2020). Algumas evidências que tendem a corroborar essa hipótese incluem: 1) clastos intrabacinais na DF-3 com composição litológica, origem deposicional primária e deformação interna similar aos sedimentos deformados da DF-1 e DF-2; e 2) estruturas de deformação dentro dos clastos intrabacinais na DF-3 foram formadas antes dos clastos, pois não mostram relação com estruturas que afetam tanto a matriz quanto os clastos. Os clastos intrabacinais foram interpretados como remanescentes de estágios iniciais de deformação com relação à condição de deformação da DF-3 (Rodrigues et al. 2020). 


\section{Estilos estruturais nos MTDs do Grupo Itararé}

As diversas estruturas apresentadas aqui foram descritas em diferentes MTDs ao longo da borda leste da Bacia do Paraná (Fig. 1A), em sua maioria durante desenvolvimento de pesquisa de doutorado (Rodrigues 2019, Rodrigues et al. 2020). As principais estruturas são as dobras e falhas, as quais são comuns em todas as fácies deformacionais. Boudins e injetitos são relativamente comuns, porém boudins foram descritos em todas as fácies deformacionais, ao passo que injetitos foram docu- mentados apenas nas DF-2 e DF-3. Feições indicativas de cisalhamento em laminações/camadas, matriz e clastos intrabacinais, bem como outros tipos de deformação na borda desses clastos mostram relativa recorrência na DF-2 e, principalmente, DF-3 (Rodrigues et al. 2020). A fim de melhor apresentar os diferentes estilos de deformação, as estruturas foram divididas em quatro estilos estruturais: 1) compressivo (dobras e falhas inversas); 2) distensivo (falhas normais e boudins; 3 ) cisalhante (feições tipo S-C-C', estruturas em quadrante e sigma etc.); e
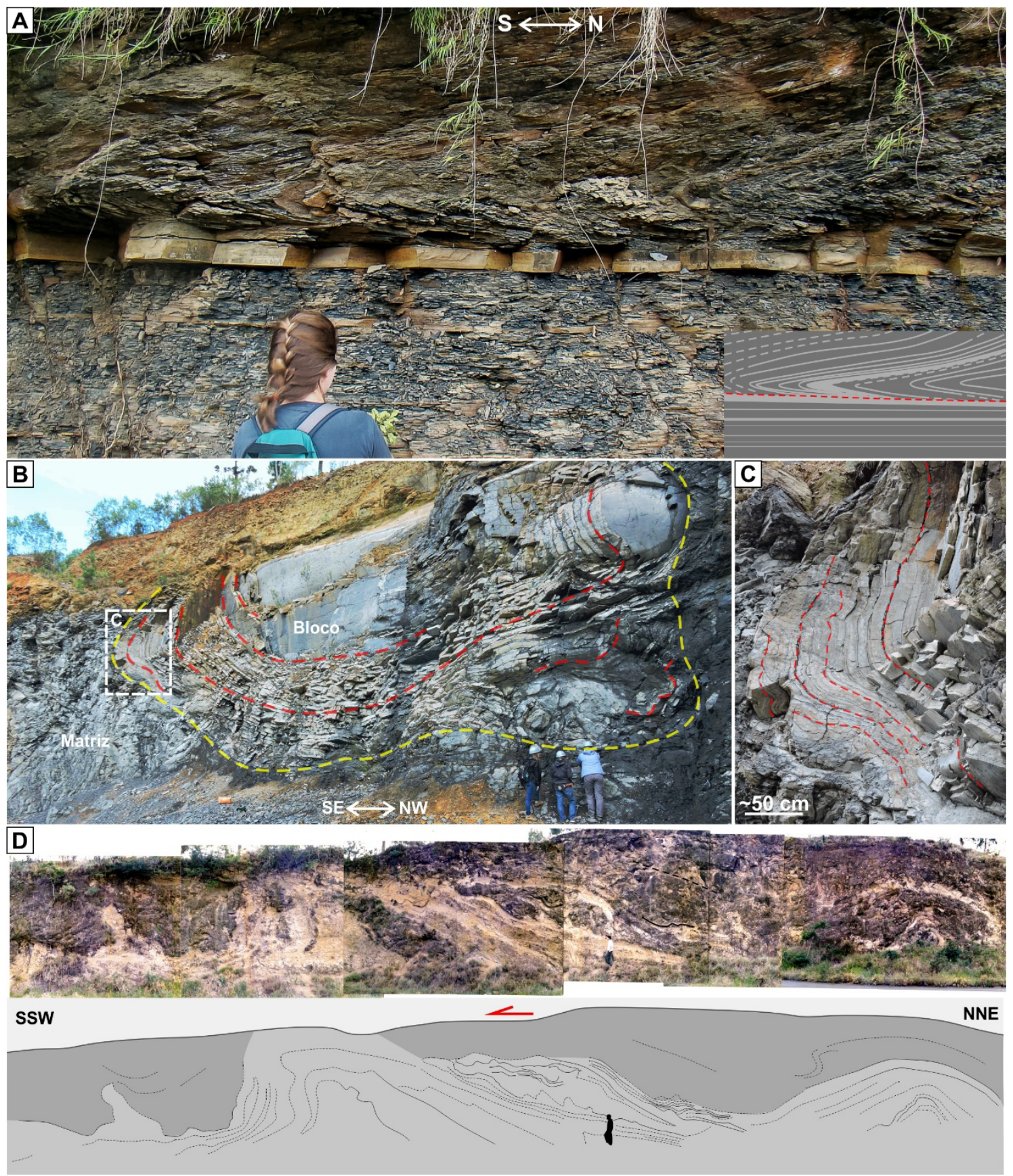

Figura 2 - A) Dobra recumbente métrica em ritmito (linha vermelha no esboço indica superfície de deslizamento na base do MTD, abaixo da qual o acamamento não se encontra deformado; localidade 11). B) Dobra fechada decamétrica com dobras decimétricas a métricas associadas (marcadas por algumas linhas tracejadas em vermelho; C) em grande bloco de ritmito (delimitado por linha amarela) em meio a diamictito (localidade 9). D) Dobras simétricas e assimétricas em diamictito, com dimensões métricas a decamétricas (localidade 2; modificado de Mottin et al. 2018). Seta vermelha indica sentido do movimento. 
4) liquefação/fluidificação/injeção (injetito, injeção clasto-matriz). Além das estruturas e feições de deformação citadas, clastos intrabacinais (grânulos a blocos) e matriz presente em MTDs maduros e evoluídos (DF-2 e DF-3, respectivamente) também são considerados produtos da deformação dos sedimentos durante o fluxo gravitacional (Rodrigues et al. 2020). Além disso, as demais estruturas, como dobras, falhas, feições de cisalhamento, entre outras, também foram documentadas dentro dos clastos intrabacinais e na matriz. Falhas e, às vezes, falhas associadas a dobras de arrasto ou de propagação podem deformar tanto clastos quanto a matriz. Também há feições de cisalhamento que deformam a borda dos clastos juntamente com a matriz em seu entorno.

\subsection{Estilo compressivo}

\section{Dobras}

As dobras mostram geometria diversa, podendo ser cilíndricas a suavemente curvilíneas e foram classificadas como suaves a cerradas (Figs. 2 e 3), raramente isoclinais, e simétricas ou assimétricas (Figs. 2A, 2D e 3AD). As dobras simétricas tendem a mostrar plano-axial vertical com eixo horizontal (dobras horizontais; Figs. $2 \mathrm{C}$ e $3 \mathrm{~A}$ ), enquanto as dobras assimétricas mostram eixos e planos-axiais com orientação variando de inclinados a horizontais (dobras recumbentes; Fleuty 1964) (Figs. 2A, 2D, 3B e 3D). Foram identificadas ainda, dobras harmônicas a desarmônicas (Fig. 3C) e, localmente, policlinais. A charneira das dobras tende a ser arredondada.

Tais estruturas ocorrem em diferentes litotipos remobilizados, como arenitos, ritmitos e folhelhos; assim como, em grandes blocos intrabacinais (large intrabasinal clasts - IC, Rodrigues et al. 2020) e em seixos a blocos desses mesmos litotipos identificados, respectivamente, dentro das seções estratigráficas e dispersos em diamictito, ou até mesmo na matriz bandada de diamictitos. Dobras identificadas em blocos podem deformá-los com um todo e definir a sua forma ou parcialmente, como em casos de dobras associadas a falhas, ou ainda deformar as camadas internas dos blocos. Em termos de dimensões, as dobras mostram amplitude e comprimento de onda de poucos milímetros (Figs. 4C, 5A e 5C) a mais de dezenas de metros (Figs. 2B e 2C). Não se descarta dobras ainda maiores, tendo em vista a exposição limitada em afloramento ou a ocorrência dentro de blocos com dezenas de metros (Fig. 2B).

Por vezes, as dobras ocorrem associadas a falhas, como dobras de arrasto (Fig. 5C) ou dobras de propagação de falhas (Figs. 4, 5, 6C e 7B). Também foram documentados boudins simétricos em flancos de algumas dobras (Figs. 3D e 9A), comumente com espessamento da charneira. Localmente, fragmentos líticos e de plantas, com forma alongada, ocorrem orientados segundo o plano-axial na charneira de algumas dobras. Além disso, ocorre pontualmente alguns tipos particulares, tais como dobras sem raiz, dobras parasíticas e dobras monoclinais.

\section{Falhas inversas}

As falhas inversas podem ser sintéticas ou antitéticas em relação à direção de fluxo, como definido a partir de indicadores cinemáticos, tais como vergência de dobras e boudins assimétricos, entre outros (Rodrigues et al. 2021). Além disso, estas falhas mostram padrão retilíneo (Figs. 4 e 5) a anastomosado (Fig. 6) e podem ocorrer como planos individuais (Figs. 4A e B) ou zonas de falhas, com espessura de poucos milímetros a vários metros (Fig. 6A). Em termos de ângulo de mergulho, as falhas inversas variam de baixo a médio ângulo (até cerca de $50^{\circ}$ ). Porém, as falhas inversas de baixo ângulo (falhas de empurrão) são as mais comuns. Em zonas de falhas inversas foram identificadas falhas sub-horizontais e algumas falhas normais associadas. Dobras de propagação de falhas e dobras de arrasto ocorrem comumente associadas às falhas inversas, principalmente quando essas últimas deformam intervalos ou blocos acamadados (Figs. 4, 5 e 6C). Assim como as dobras, as falhas inversas afetam diferentes litotipos, como arenitos, ritmitos e folhelhos, que ocorrem tanto como intervalos deformados devido à remobilização talude abaixo, como seixos a blocos dispersos em diamictito, ou a matriz dos diamictitos. No caso de seixos a blocos, foram identificadas falhas inversas tanto restritas às camadas internas (Figs. 4, 5A, 5C e 6C) desses clastos quanto deformando-os juntamente com a matriz (Fig. 5B).

$\mathrm{O}$ deslocamento ao longo das falhas varia de menos de 1 milímetro a alguns metros, enquanto as falhas variam de alguns milímetros a algumas dezenas de metros de comprimento. Contudo, tanto o tamanho quanto o deslocamento das falhas podem ser de dezenas de metros ou mais, uma vez que, a exposição pode ser limitada ou o tipo de material deformado (como matriz de diamictito) muitas vezes não permite esse tipo de avaliação (Fig. 6A). Falhas com deslocamento de pouco milímetros foram denominadas microfalhas, e, localmente, ocorrem num conjunto subparalelo, cujo aspecto se assemelha a clivagem ou foliação (Figs. 4 e 6C).

Algumas falhas inversas são marcadas por microfalhamento ou arrasto de argila e/ou areia formando concentrações em bandas de espessura milimétrica. Tais estruturas foram identificadas como resultado de smear de argila e ou areia (Rodrigues et al. 2020). Com base na composição do sedimento concentrado ao longo das bandas e sua continuidade, esse tipo de falha foi classificado em banda de smear de argila (clay smear) contínuo (Figs. 6A e 6B) e banda de smear de argila e areia (clay/sand smear) descontínua (Fig. 6C). O termo argila foi usado por Rodrigues et al. (2020) com relação à granulometria dos sedimentos. Bandas de smear de argila contínuo ocorrem em diamictitos com matriz síltico- a areno-argilosa, comumente, como zonas de falhas/ bandas com espessura milimétrica a métrica e padrão anastomosado. Esse tipo de falha mostra feição similar a bandas de deformação geradas em sedimentos com mais de $40 \%$ de argila descritas por Fisher \& Knipe (2001). 

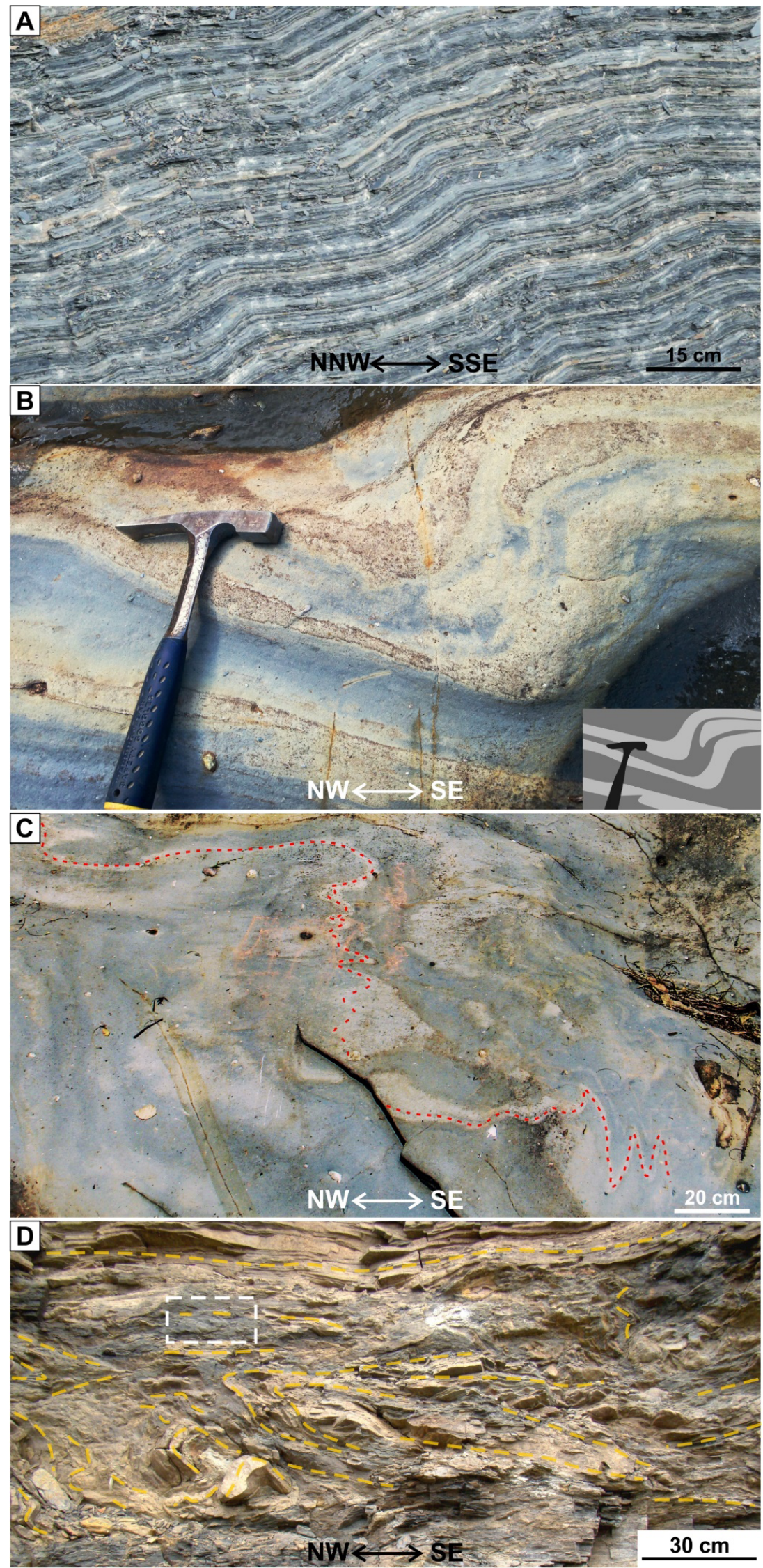

Figura 3 -A) Dobras simétricas suaves a abertas em ritmito basculado (localidade 18; Rodrigues et al. 2020). B) Dobras assimétricas (Rodrigues et al. 2020) e C) complexas (ressaltadas por linha tracejada vermelha) em diamictito com matriz bandada (localidade 1). D) dobras assimétricas rompidas (acamamento realçado por linhas tracejadas em amarelo) e, pontualmente, com flancos boudinados (detalhe dos boudins na Fig. 9A, cuja posição está indicada por retângulo branco) em ritmito (localidade 13). 

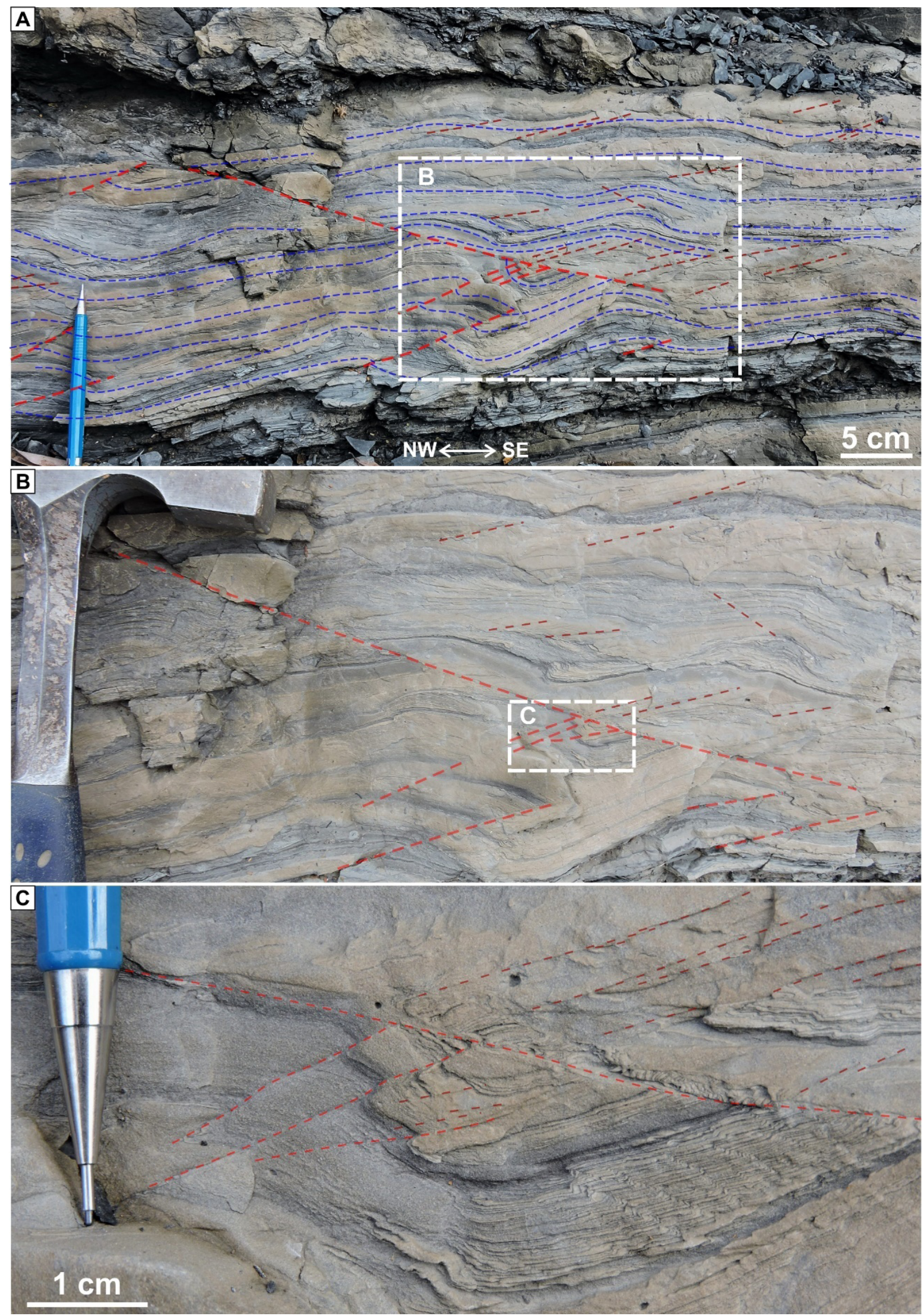

Figura 4 - Dobras associadas a falhas que afetam algumas camadas de bloco de ritmito identificado dentro de diamictito (localidade 9): A) Camadas de ritmito (realçada por linhas tracejadas azuis) deformadas por dobras, dobras de propagação de falhas e dobras de arrasto associadas a falhas de empurrão e microfalhas. B) e C) Detalhes das dobras, falhas e microfalhas; notar dobras milimétricas em flanco de dobra centimétrica $(C)$. Algumas falhas de empurrão e microfalhas encontram-se realçadas por linhas tracejadas em vermelho e vermelho escuro, respectivamente (A- C). 

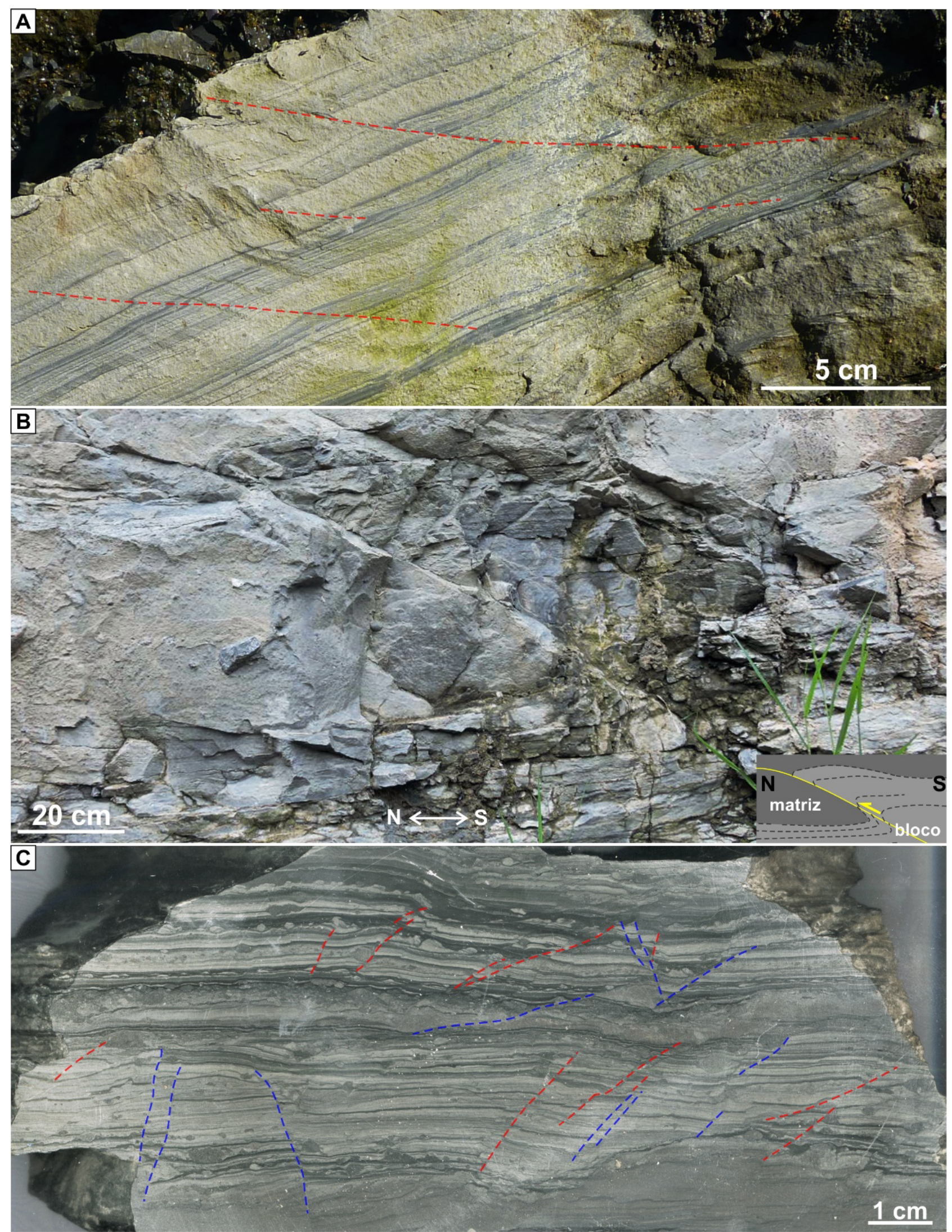

Figura 5 - A) Dobras de propagação de falhas em bloco de ritmito em diamictito (localidade 9). B) Dobra de propagação de falha em bloco de ritmito em diamictito (localidade 12; adaptada de Rodrigues et al. 2020). C) Falhas normais e inversas com dobras de arrasto em bloco de ritmito identificado em diamictito (algumas falhas normais e inversas foram ressaltadas por linhas tracejadas azuis e vermelhas, respectivamente; amostra coletada na localidade 12). 

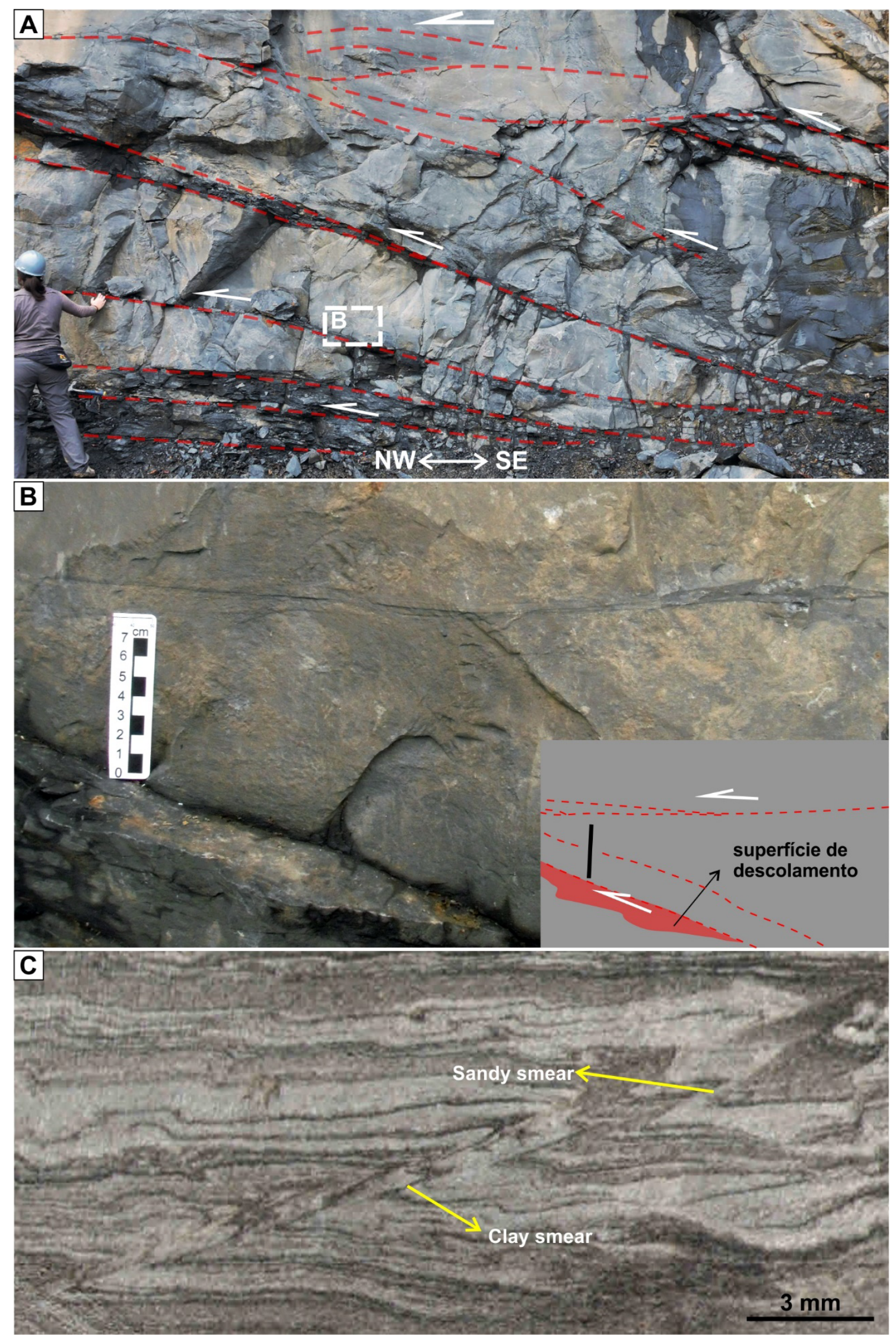

Figura 6 - A) Falhas inversas sub-horizontais a inclinadas anastomosadas com clay smear contínuo (planos principais ressaltados por linhas tracejadas vermelhas) em matriz de diamictito (localidade 12; modificado de Rodrigues et al. 2020). B) Detalhe das falhas/bandas com clay smear; em algumas falhas um plano de descolamento,por vezes com estrias (localidade 12). C) Falhas inversa com clay/ sand smear descontínuo em ritmito (amostra de bloco intrabacinal da localidade 9; modificado de Rodrigues et al. 2020). 

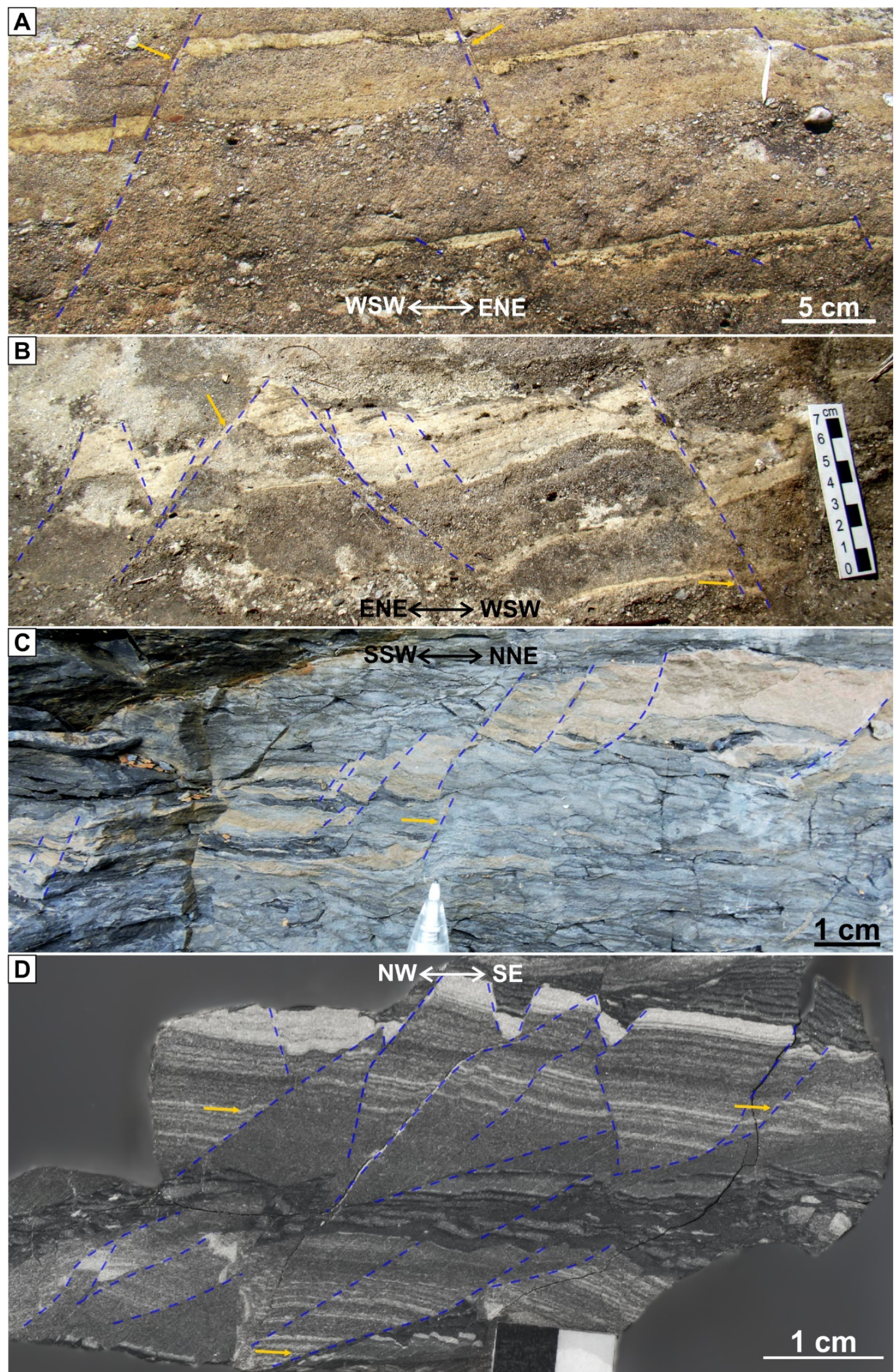

Figura 7 - Falhas normais (ressaltadas por linhas azuis tracejadas) em grande bloco intrabacinal de arenito médio a grosso com laminações de areia fina, com formação local de smear de areia (A e B; localidade 1). Falhas normais em ritmito, com ocorrência ocasional de smear de areia e argila (C - bloco de ritmito em diamictito da localidade 9; e D, amostra da localidade 10). Alguns exemplos de smear de areia e argila são indicados por setas amarelas nas fotografias (A-D). 

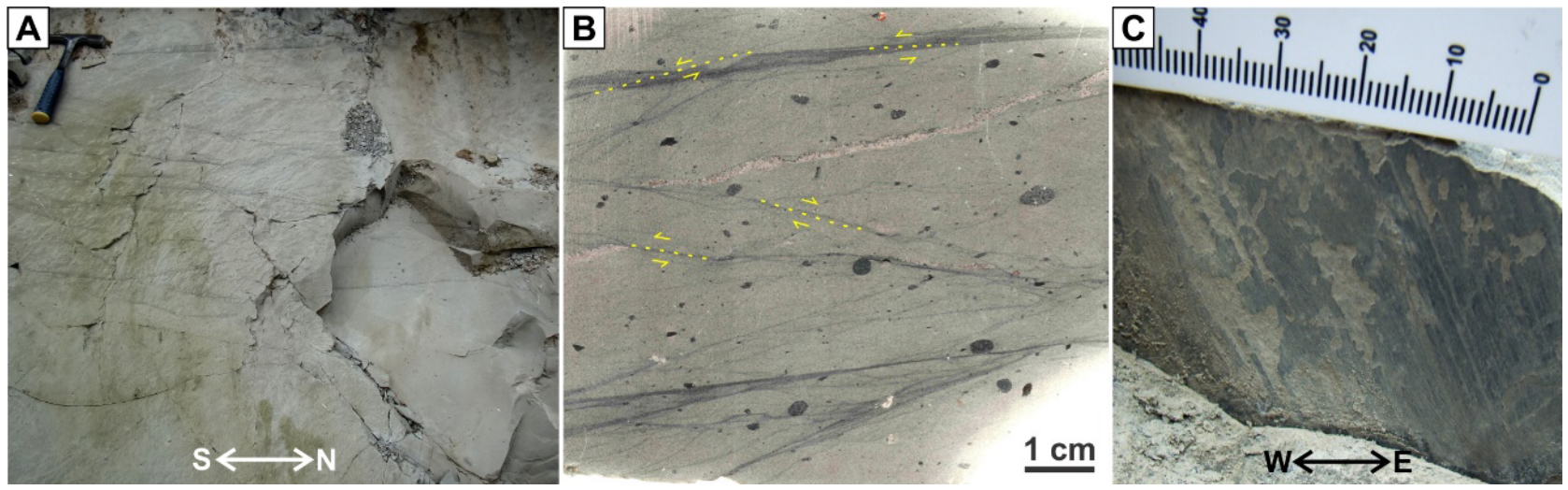

Figura 8 - A) e B) Falhas normais anastomosadas associadas a zonas de cisalhamento subhoriontais com clay smear contínuo em matriz de diamictito (B - amostra, modificada de Rodrigues et al. 2015) e B) que mostram, por vezes, plano de descolamento estriado (localidade 8).

Algumas dessas bandas podem exibir superfícies de descolamento com estrias que formam propriamente planos de falhas; porém, tende a ser difícil a identificação de steps ou outras feições indicativas de cinemática nessas superfícies. A deformação de blocos intrabacinais (Fig. 5B), por vezes, com dobras de arrasto ou de propagação de falhas associada, e a geometria dessas estruturas são importantes auxiliares na definição da cinemática. Quando identificado, o deslocamento ao longo dessas estruturas varia de poucos milímetros a cerca de $1 \mathrm{~m}$ (Fig. 5B). Nesse último caso, a ocorrência de superfície de descolamento é comum. Por sua vez, as bandas de smear de argila descontínuas ocorrem associadas com smears de areia em ritmitos e são similares às estruturas discutidas por Kristensen et al. (2013), as quais são geradas quando laminações argilosas e arenosas são arrastadas por falha. Dobras de arrasto ou de propagação de falhas ocorrem comumente associados às bandas de smear de argila e areia, como resultado da deformação das laminações de ritmito por esse tipo de falha inversa (Fig. 6C). Casos de smear de argila e areia descritos ocorrem ao longo de falhas com deslocamento de poucos milímetros, como nas microfalhas (Figs. 4 e 6C), a poucos centímetros (Figs. 4A e 4B).

\subsection{Estilo distensivo}

\section{Falhas normais}

As falhas normais se assemelham em vários aspectos às falhas inversas. Em relação a direção de fluxo, tais falhas podem ser sintéticas ou antitéticas (Rodrigues et al. 2021). Essas estruturas também podem ocorrer como planos individuais ou zonas de falhas (espessura milimétrica a métrica) com padrão retilíneo (Figs. $5 \mathrm{C}$ e 7 ) a anastomosado (Fig. 8A). Além disso, podem formar pares conjugados (Figs. 7A, 7B e 7C). O ângulo de mergulho das falhas normais varia de baixo a subvertical $\left(8^{\circ}\right.$ a $\left.89^{\circ}\right)$; contudo, predominam falhas com mergulho médio (entre $40^{\circ}$ e $60^{\circ}$ ). Em zonas de falhas normais podem ocorrer falhas sub-horizontais e, pontualmente, falhas inversas associadas. $\mathrm{O}$ deslocamento ao longo dessas falhas varia de menos de 1 milímetro a alguns metros, enquanto sua extensão varia de poucos milímetros a algumas dezenas de metros. Em alguns locais, falhas normais resultaram em basculamento das camadas, que pode ser cerca de $10^{\circ}$ ou mais. Falhas normais também ocorrem em intervalos ressedimentados e dentro blocos de arenitos, ritmitos e folhelhos, além de deformarem a matriz de diamictitos e, por vezes, alguns blocos intrabacinais. Dobras de arrasto podem, eventualmente, ocorrer associadas a essas falhas.

De modo similar às falhas inversas, as falhas normais em alguns MTDs são caracterizadas por microfalhamento ou arrasto (smear) de argila e/ou areia. As bandas associadas a distensão mostram concentrações descontínuas de argila e/ou areia ao longo de falhas geradas em arenitos (Figs. 7A e 7B) e ritmitos (Figs. 7C e 7D), e concentrações contínuas de argila, em diamictitos (Fig. 8). Ambos os tipos de bandas de smear mostram espessura de poucos milímetros. As bandas de smear de argila contínuas ocorrem como zonas de falhas sub-horizontais ou de baixo ângulo com espessura milimétrica a métrica e padrão anastomosado, onde falhas sub-horizontais e, por vezes, inversas ocorrem associadas às falhas normais (Figs, 8 A e 8B). Ocorrem ainda planos individuais e zonas de falhas, com espessura milimétrica a centimétrica, que são subparalelos a paralelos, com ângulo de mergulho médio a alto e, por vezes, superfície de descolamento estriada (Fig. 8C). A cinemática e quantidade de deslocamento nas bandas de smear de argila contínuas também é difícil de definir por se formarem na matriz de diamictitos. Neste caso, também se buscou indicações onde essas estruturas afetam bandamento da matriz e clastos intrabacinais no diamictito, e até mesmo injetitos de areia (Fig. $8 \mathrm{~B}$ ), além da geometria dessas estruturas. Localmente, foi descrita falha normal com núcleo de argila cisalhada com espessura centimétrica.

\section{Boudins}

Os boudins documentados foram classificados como simétricos ou assimétricos. Os boudins simétricos mostram comprimento e espessura variando de alguns centímetros a vários metros e ocorrem em camadas de arenito maciço ou estratificado hospedadas em argilito (dentro de intervalo de ritmito) ou diamictito (Figs. 9A e 9B, respectivamente). 

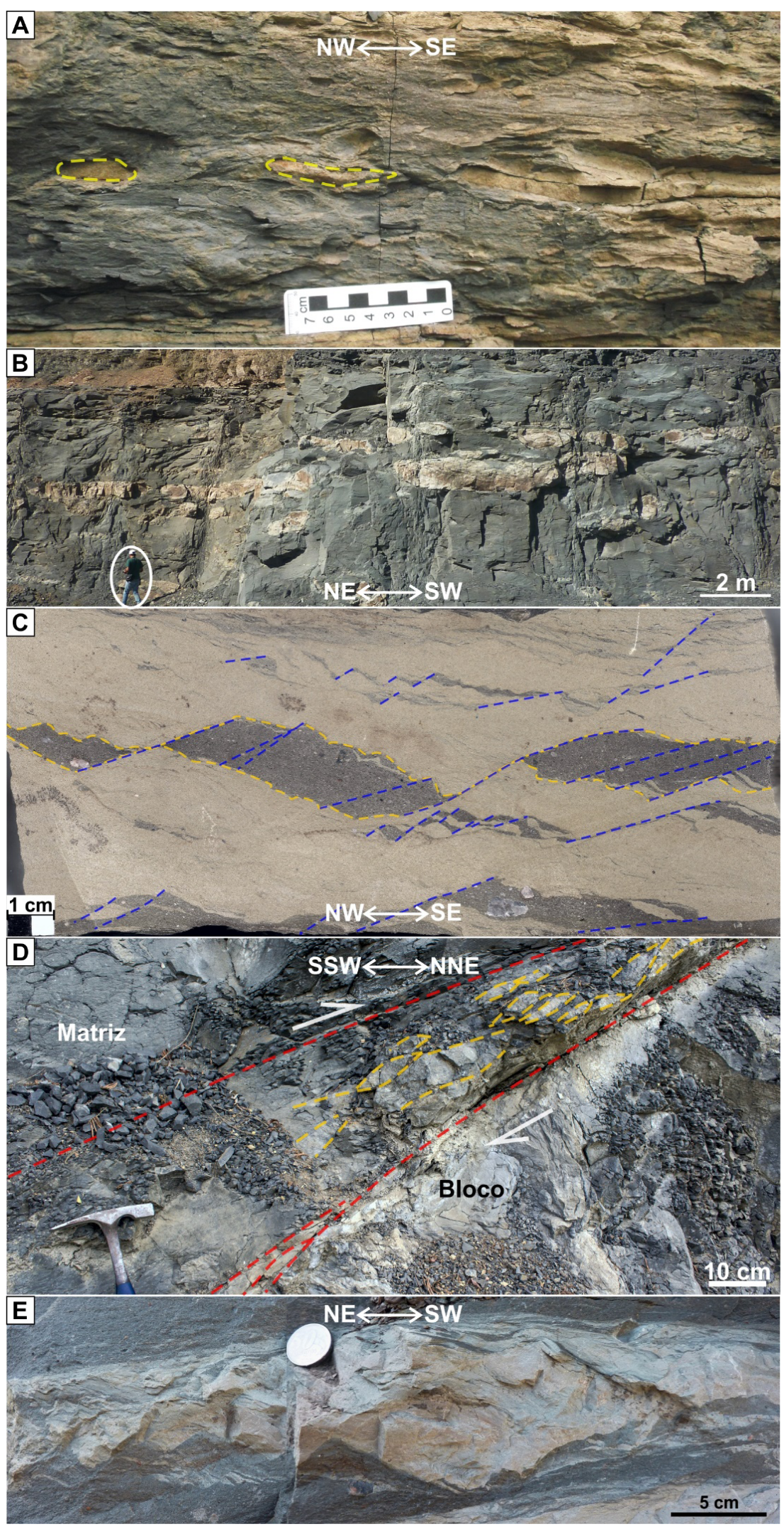

Figura 9 - Diferentes tipos de boudins identificados em MTDs: A) Boudins simétricos (tipo drawn boudin; realçados por linhas amarelas tracejadas) em camadas arenosas de ritmito (boudins gerados em flanco de dobras, ver Fig. 3D; localidade 13; modificado de Rodrigues et al. 2020). B) Boudins simétricos (tipo drawn boudin) em arenito dispersos em diamictito (localidade 6). C) Boudins assimétricos (tipo shearband boudin) em camada argilosa hospedado em camada argilosa; boudinagem gerada em ritmito (amostra da localidade 10; modificado de Rodrigues et al. 2020). D) Zona de cisalhamento inversa com lentes de arenito com padrão sigma, possivelmente boudins assimétricos (tipo shearband boudins), gerada no contato entre bloco de ritmito e matriz de diamictito (localicade 9). E) Boudin simétrico em camada arenosa deformado por falhas normais e cisalhamento nas bordas, hospedada em diamictito (localidade 6). 
Alguns boudins simétricos ocorrem ao longo de flancos de dobras recumbentes, as quais podem mostrar espessamento da charneira (Figs. 3D e 9A). As camadas de argilito hospedeiras podem ou não mostrar laminação preservada. A forma dos boudins simétricos é alongada e de lentes convexas com superfície arredondada, sem superfície inter-boudin e, localmente, com necking e foram classificados por Rodrigues et al. (2020) em drawn boudins (com base em Goscombe et al. 2004).

Por sua vez, os boudins assimétricos ocorrem em ritmitos e diamictitos heterogêneos (Figs. 9C e 9D, respectivamente), comumente associados a zonas de cisalhamento. Essas estruturas resultam da boudinagem por fraturas de cisalhamento mais ou menos restritas as camadas deformadas. Foram identificados boudins assimétricos em camadas argilosas hospedadas em arenito (dentro de intervalo de ritmito; Fig. 9C), e por vezes, em camadas arenosas hospedadas em camadas argilosas ou diamictito (Fig. 9D). Tais boudins mostram forma arredondada, sigmoide e lenticular, com superfície inter-boudin reta a levemente curvada e, comumente, associada com bandas de cisalhamento que compreendem smear de argila ou areia (Fig. 9C). A rotação dos blocos de boudins é para trás, ou seja, antitético ao cisalhamento geral que forma esses boudins. Já o cisalhamento nas falhas dos boudins é sintético com respeito ao cisalhamento geral. Com base nas características geométricas e cinemáticas, esses boudins foram classificados por Rodrigues et al. (2020) como shearband boudins (com base em Goscombe et al. 2004).

Tanto os boudins simétricos quanto os assimétricos podem mostrar rotação, mudanças de forma e deslocamento devido a deformação pós-boudinagem, tais como cisalhamento das margens de blocos de boudins e falhas (Fig. 9E). Tais deformações pós-boudinagem ocorrem restritas ao $M T D$ e, por vezes, limitada a intervalos específicos ou porções dentro do $M T D$; portanto, foram interpretados como deformação do fluxo de massa.

\subsection{Estilo cisalhante}

As estruturas e feições classificadas como estilo cisalhante mostram similaridades geométricas a diferentes estruturas descritas em zonas de cisalhamento tectônicas (e.g., Fossen 2016). Em zonas de cisalhamento normais e inversas foram descritas feições com geometria tipo par S-C-C' (Fig. 10), que ocorrem em ritmitos ou em resquícios de ritmito em diamictitos. Nessas zonas de cisalhamento bandas $\mathrm{S}$ consistem nas laminações arrastadas de acordo com o sentido de cisalhamento ao longo da banda de cisalhamento C'. Por sua vez, as bandas de cisalhamento C' mostram smear de argila e, por vezes, de areia. As bandas de cisalhamento C' com predomínio de argila podem apresentar superfícies de descolamento com estrias. As bandas de cisalhamento $\mathrm{C}$, quando presentes, consistem em superfícies de cisalhamento, com ou sem smear de argila, que limitam essas zonas.

Outras estruturas resultantes de cisalhamento e que são importantes indicadores cinemáticos foram documentadas. Essas feições incluem: 1) estruturas em quadrantes (Fig. 11A) geradas por cisalhamento de laminações ao redor de clastos rígidos (como seixos de granito). São caracterizadas por feições compressivas e distensivas ao redor desses clastos, e que são similares às estruturas em quadrantes de zonas miloníticas (ver Fossen 2016). 2) Estrutura em sigma ( $\sigma$; Fig. 11B), que consiste em bloco assimétrico de arenito em matriz coesiva e com geometria de sigma ou "fish", similares às estruturas chamadas pseudo-sigma por Ogata et al. (2016). 3) Superfícies de descolamento intraestratal estriadas, as quais foram descritas em planos de acamamento de argilitos/folhelhos. 4) Fragmentos irregulares resultantes de cisalhamento e ruptura de acamamento/laminação em diamictitos heterogêneos (com matriz bandada; Fig. 11C), que são similares às estruturas descritas e interpretadas por Ogata et al. (2012) como produto de deformação progressiva de sedimentos acamadados. 5) Laminação e fragmentos sedimentares com aspecto cisalhado (Figs. 11C e 11D), que foram identificados em ritmitos e diamictitos heterogêneos e que contribuem para $\mathrm{o}$ aspecto bandado da matriz desses diamictos.

Cisalhamento dentro dos MTDs também resultou na orientação preferencial do eixo mais longo dos clastos (intrabacinais e extrabacinais) e deformação das bordas de clastos intrabacinais (Fig. 12). Entre as deformações na borda dos clastos intrabacinais, foi identificado cisalhamento que resultou em porções de sedimentos incorporados na matriz (Figs. 12A e 12B). Essas feições são geometricamente similares a deformações ao redor de porfiroclastos (e.g., Fossen 2016). O cisalhamento nas bordas de clastos também podem gerar sulcos/estrias (Fig. 12C) similares aos descritos por Ogata et al. (2012 e 2014c).

\subsection{Estilo de liquefação/fluidificação/injeção}

A deformação associada a esse estilo inclui mútua injeção entre materiais dos clastos e da matriz circundante (Fig. 13), descrita nas bordas de clastos intrabacinais e, principalmente, os injetitos. Os injetitos correspondem a injeções de areia que ocorrem como diques (Figs. 14A, 14B e 14C) e, mais raramente, como soleiras (Figs. 14A e 14E). A composição mais comum dos injetitos varia de areia muito fina a média, porém também foram descritos injetitos com areia grossa e silte. Essas injeções variam de espessura de poucos milímetros a decímetros e foram identificadas em uma variedade de rochas hospedeiras tais como diamictitos (bandados e maciços), folhelhos, ritmitos e arenitos (Figs. 14 e 15). As soleiras são tabulares, com bordas mais ou menos regulares (Fig. 14A) e, localmente, dobradas (Fig. 14E). Por outro lado, os diques mostram bordas regulares a irregulares, forma tabular a anastomosada e, por vezes, padrão en echelon. Ademais, os diques de areia, comumente, cortam vários metros de sucessão estratigráfica.

Dentro dos injetitos podem ocorrer fragmentos arrancados e/ou englobados da rocha hospedeira (Figs. 14C e 14D). Porções de rocha hospedeira podem ocorrercercadas por enxame de injetitos, formando brecha (Fig. 15A-C). Os conjuntos de diques costumam mostrar orientação consistente. Porém, alguns conjuntos de injetitos associados a brechas mostram orientação aleatória. Em algumas ocorrências, foram ainda descritas feições sugestivas de fluxo da areia dentro dos injetitos (e.g., Callot et al. 2008) e, por vezes, com deformação dos fragmentos ou porções da rocha hospedeira (Fig. 15B). 

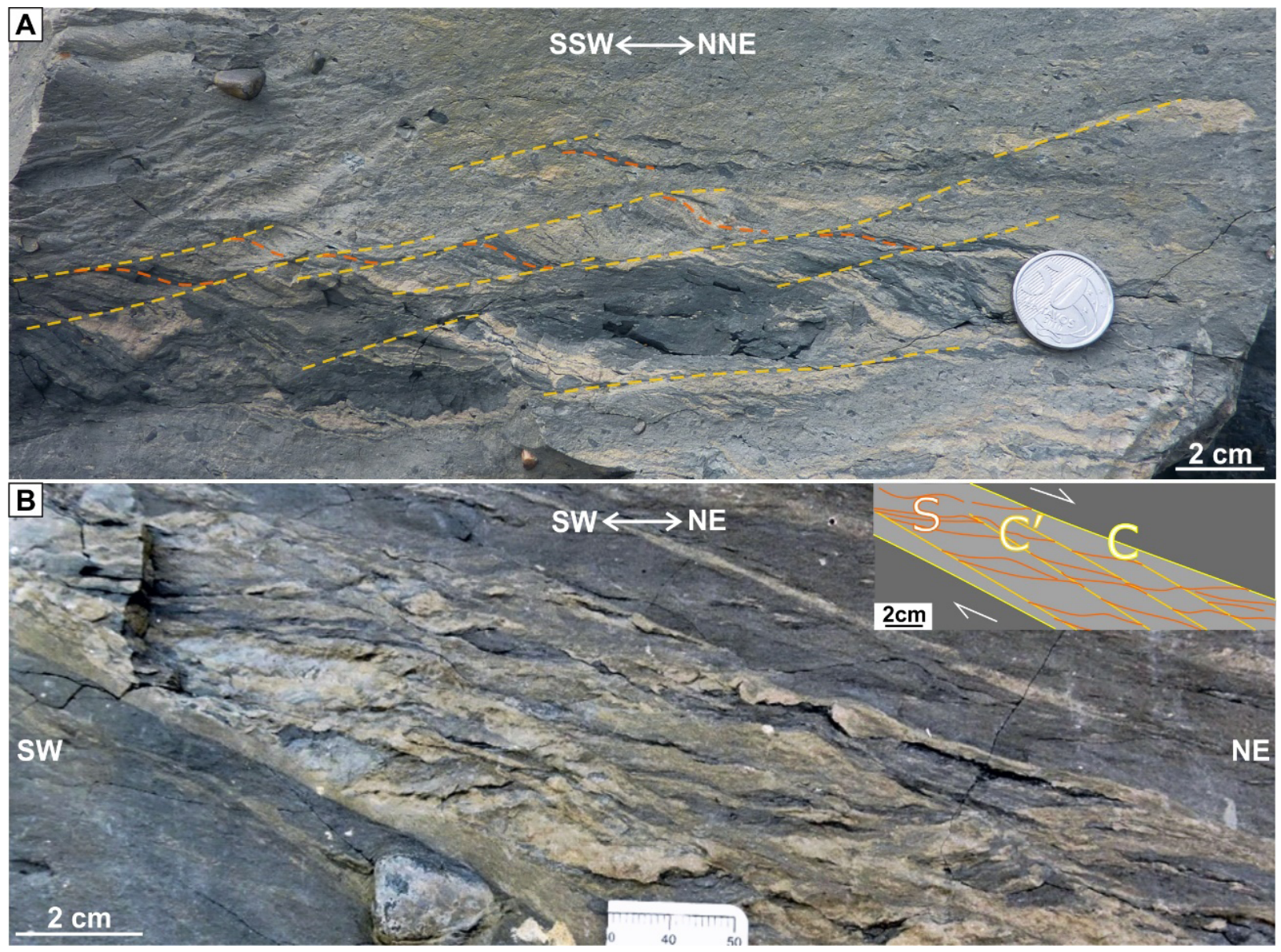

Figura 10 - A) Falhas normais com feições tipo S-C-C' e clay/sand smear em bloco de ritmito em diamictito. B) Zonas de falhas normais com feições tipo S-C-C' e clay/sand smear em resquícios de camada de ritmitos dispersa em diamictito. As laminações arrastadas pelas falhas formam geometria $\mathrm{S}$ (alguns indicadas por linhas laranjas), as falhas que as deformam correspondem as bandas de cisalhamento C' (indicadas por linhas amarelo escuro) e, quando presente, falhas de que delimitam o intervalo deformado corresponde a bandas C (linhas amarelo-claro). Exemplos da localidade 9.

Localmente, também foram descritos injetitos subparalelos a bandas de smear de argila contínuo ou preenchendo superfícies de descolamento dessas falhas. Quando identificadas, a unidade arenosa parental dos injetitos corresponde a camadas deformadas, relictos de camadas deformadas ou clastos alóctones. Os injetitos foram ainda observados cortando estruturas geradas durante o evento de fluxo em massa, deformados por estruturas do próprio fluxo em massa (Fig. 8B) ou ambos.

\section{Diversidade de estruturas em MTDs e possíveis fatores associados}

A grande variedade de estruturas documentadas em MTDs do Grupo Itararé pode ser considerada uma característica comum desse tipo de depósito (e.g., Farrell 1984, Martinsen 1994, Bull et al. 2009, Alsop \& Marco 2011, 2014, Ogata et al. 2012, 2014 a,b,c , Sobiesiak et al. 2016, Jáblonska et al. 2018). Assim como observado no Grupo Itararé, dobras e falhas são as principais estruturas descritas em MTDs e podem mostrar diferentes geometrias, orientação e cinemática (e.g., Alsop \& Marco 2011, 2013, 2014, Dykstra et al. 2011, Sobiesiak et al. 2016, Rodrigues et al. 2020).
Vários fatores podem influenciar a variedade de estruturas dos MTDs, incluindo: 1) gradiente e morfologia do talude e fundo marinho (e.g., Strachan 2002, Lucente \& Pini 2003, Bull et al. 2009); 2) características das camadas sedimentares (composição, granulometria, grau de litificação, porosidade, permeabilidade e pressão de fluidos, entre outros) e variação de reologia (e.g., Frey-Martinez et al. 2006, Cosgrove 2007, Waldron \& Gagnon 2011, Odonne et al. 2011, Alsop \& Marco 2013, Ogata et al. 2014a,b, Alsop et al. 2016); 3) taxa de deformação (e.g., Cosgrove 2007); 4) orientação e distribuição da tensão (e.g., Hansen 1971, Farrell 1984, Farrell \& Eaton 1987, Elliot \& Williams 1988, Webb \& Cooper 1988, Martinsen 1989, 1994, Martinsen \& Bakken 1990, Debacker et al. 2001, 2009, Strachan 2002, 2008, Strachan \& Alsop 2006, Alsop \& Marco 2011, 2014, Jábloska et al. 2018); 5) evolução do fluxo em massa e aceleração/desaceleração do fluxo (Farrell 1984, Martinsen 1994, Martinsen \& Bakken 1990, Strachan 2002, 2008, Alsop \& Marco 2011, 2014, Alsop et al. 2016); 6) deformação progressiva (e.g., Alsop \& Marco 2013); 7) ressedimentação/retrabalhamento por mais de um evento de fluxo em massa (e.g., Alsop \& Marco 2011, Alsop et al. 2016), entre outros. 

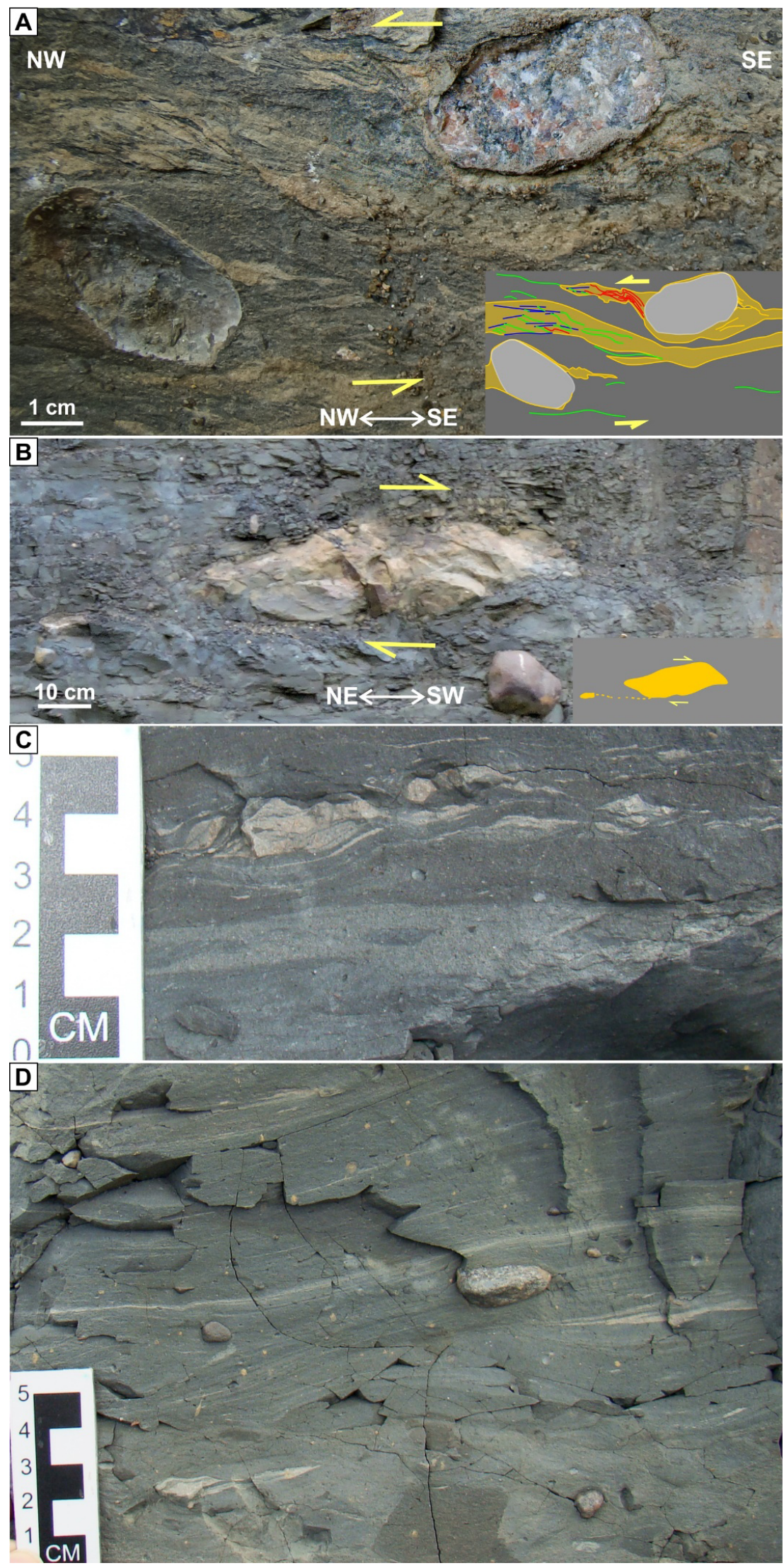

Figura 11 - Feições indicativas de cisalhamento: A) Feições tipo em quadrante geradas pelo cisalhamento de laminação de ritmito ao redor de clastos rígidos (e.g., seixo de granito, quando identificado; localidade 10). B) Bloco de arenito cisalhado com forma em sigma e trilha de fragmentos arrancados em diamictito (localidade 7; modificado de Rodrigues et al. 2020). C) e D) Resquícios de laminações arenosas em diamictito deformadas por cisalhamento que, por vezes, conferem aspecto bandado a matriz de diamictito (blocos soltos do afloramento; localidade 7; D - Rodrigues et al. 2020). 

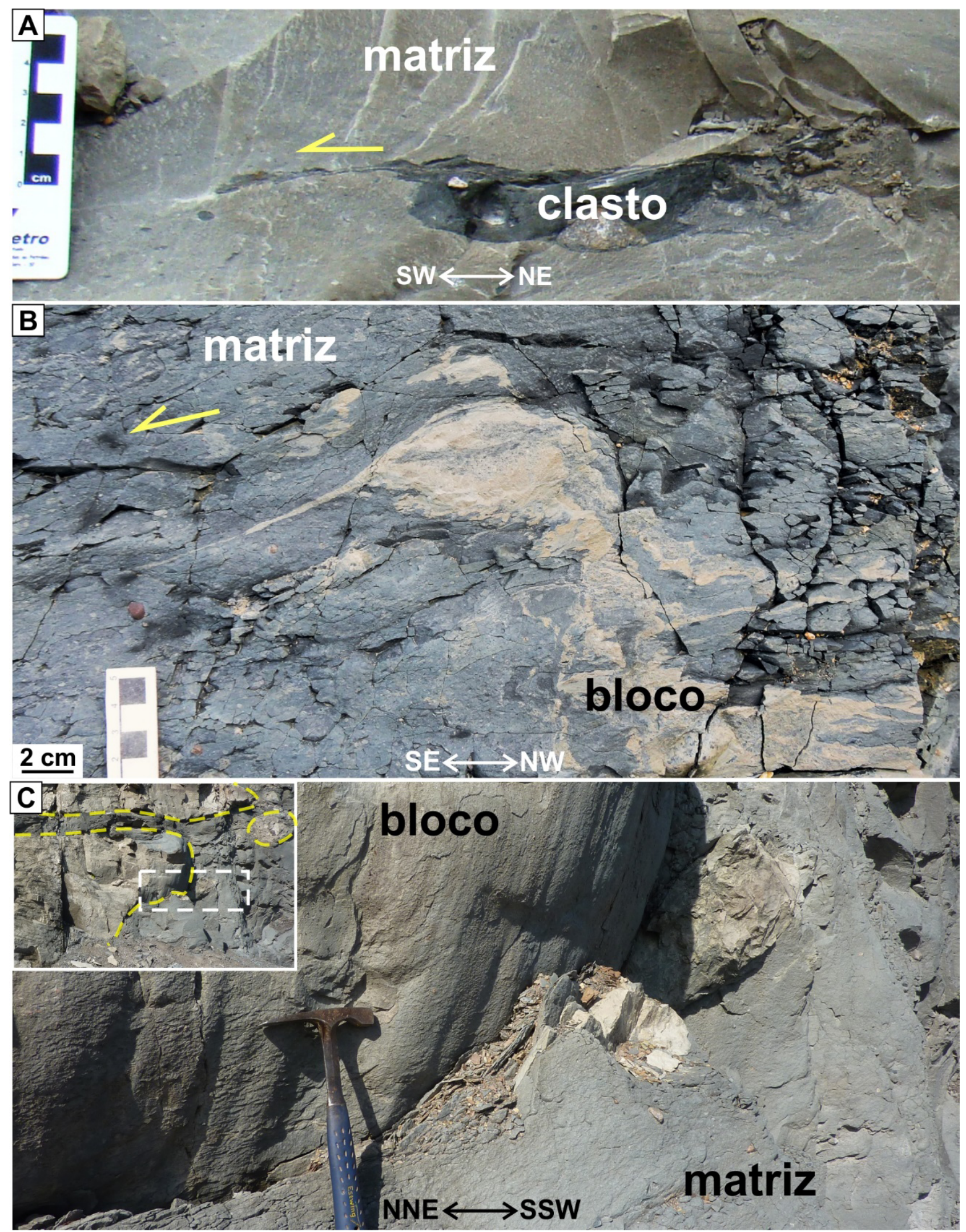

Figura 12 - A) e B) Cisalhamento na borda de clastos intrabacinais (seixo de lamito e bloco de ritmito, respectivamente) com porções de sedimentos coletados e incorporados na matriz do diamictito (localidades 8 e 9, respectivamente). C) Sulcos e estrias na borda de bloco de arenito disperso em matriz de diamictito (localidade 6; adaptado de Rodrigues et al. 2020). 


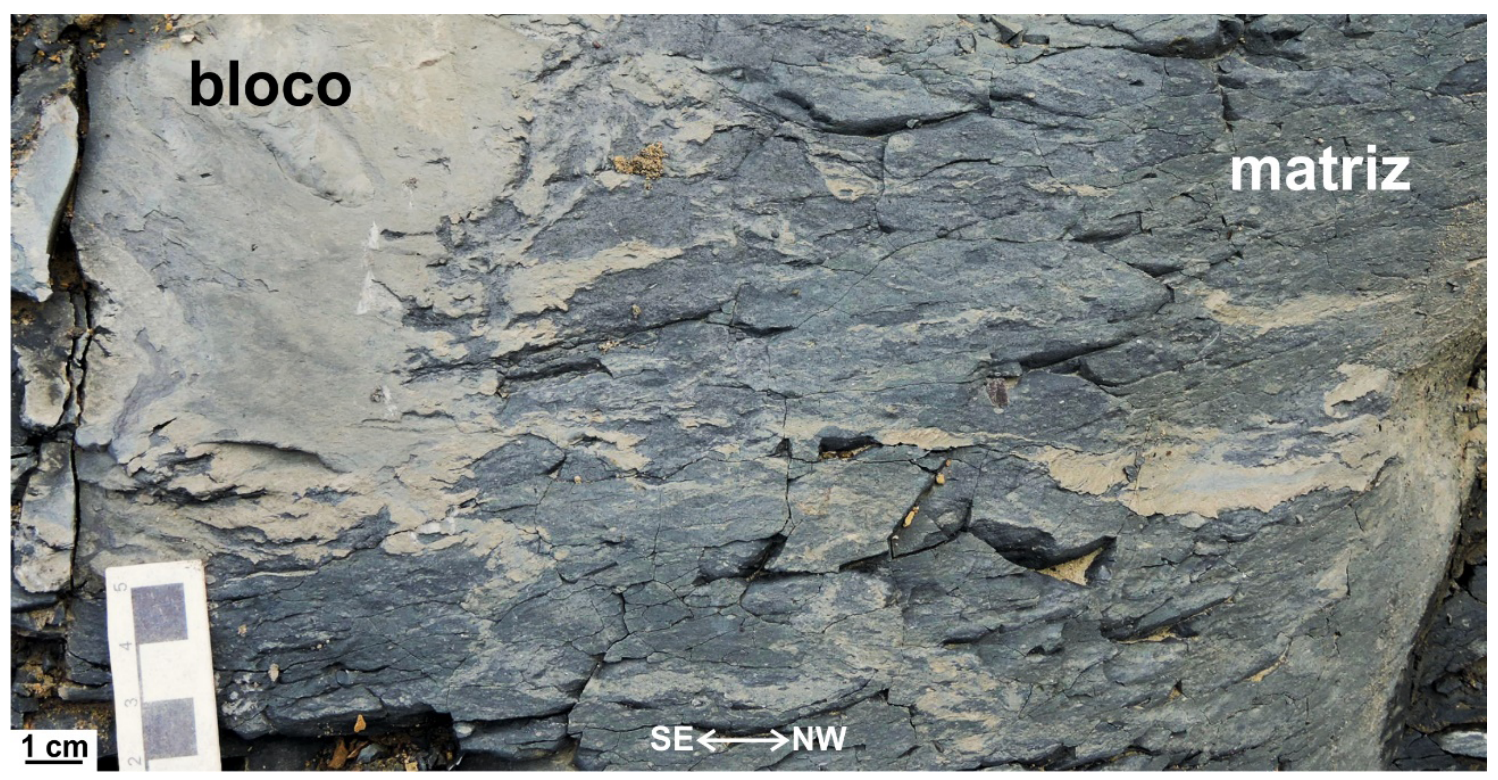

Figura 13 - Mútua injeção de sedimentos do bloco de ritmito e da matriz do diamictito (localidade 9; adaptado de Rodrigues et al. 2020).

Porém, muitas vezes é difícil determinar a relação entre a diversidade de estruturas e fatores influenciadores, principalmente em casos de limitada exposição de afloramento. No caso do Grupo Itararé, podemos citar alguns potenciais fatores.

Os fluxos gravitacionais em massa remobilizam, comumente, espessos intervalos (dezenas a centenas de metros) de sucessões estratigráficas, em diferentes regiões do talude que, consequentemente, envolvem camadas de diferentes composições e com sedimentos pouco ou não litificados (e.g., Hansen 1971, Nardin et al. 1979, Farrell 1984, Martinsen 1994, Ogata et al. 2012, Alsop \& Marco 2014, Berton \& Vesely 2016, Moscardelli \& Wood 2016, Sobiesiak et al. 2016). No Grupo Itararé, os fluxos gravitacionais em massa parecem ter resultado, principalmente, do colapso de taludes deltaicos e resedimentaram porções desde a planície deltaica até o prodelta, o que inclui fácies arenosas, heterolíticas e lamosas (e.g., Carvalho \& Vesely 2017, Valdez-Buso et al. 2019, Mottin et al. 2018, Schemiko et al. 2019). Essa variedade de fácies sedimentares envolvidas e variações reológicas dentro das camadas, relacionadas a variações de porosidade, permeabilidade, diagênese, compactação e pressão de fluídos, podem ter influenciado a diversidade de estruturas de deformação nos MTDs do Grupo Itararé. Os diferentes estilos estruturais descritos foram identificados em todos os tipos de fácies sedimentares remobilizadas. Possivelmente, a composição das camadas influencia a geometria das estruturas, porém a amostragem existente não indica estruturas com geometria específica associada exclusivamente com um litotipo. Contudo, algumas feições descritas parecem depender de determinadas características composicionais para se formarem, tais como tipo par S-C-C' (Fig. 10) e laminações cisalhadas (Figs. 11A, 11C e 11D) que parecem depender da existência de laminações de diferentes composições intercaladas ou de laminações de uma composição hospedada em camada ou material (como matriz de diamictito) de composição diferente.
Quanto as fácies deformacionais dos MTDs, verificamos uma relação parcial com a variedade de estruturas, em que há um aumento da diversidade de estruturas da fácies DF-1 para DF-3 (Rodrigues et al. 2020). Algumas feições de deformação parecem ocorrer preferencialmente ou mesmo exclusivamente em uma fácies deformacional, como aquelas relacionadas a deformação de clastos intrabacinais descritos na DF-3. Por sua vez, injetitos e feições diversas de cisalhamento foram identificados apenas nas fácies DF-2 e DF-3. Porém, as estruturas mais recorrentes, que são as dobras, falhas e boudins, ocorrem em todas as fácies deformacionais. Dobras e/ou falhas foram descritas em quase todos os afloramentos. Em alguns casos, dobras não foram identificadas na matriz de diamictito da DF-3, mas foram descritas dentro de blocos intrabacinais dispersos na matriz. Nem mesmo possíveis variações na geometria e cinemática dessas estruturas podem ser consideradas exclusivas de uma fácies deformacional. Dobras suaves a abertas e simétricas, por exemplo, foram descritas em afloramentos da fácies DF-1 (e.g., localidade 18; Fig. 3A), DF-2 (e.g., localidade 4, 5 e 13 ) e DF-3 (e.g., localidade 2 - Figs. $2 \mathrm{C}$ e 8). Dobra assimétricas abertas a fechadas também foram descritas nos diferentes tipos de fácies (e.g., DF-1 - localidade 11, DF-2 - localidades 1 e 13, DF-3 - localidade 2; Figs. 2A, $3 \mathrm{~B}, 3 \mathrm{D}$ e $2 \mathrm{D}$, respectivamente). Além disso, em diversos afloramentos foram descritas dobras com diferentes geometrias em um mesmo intervalo ou bloco intrabacinal (e.g., localidade 1- DF-2, Figs. 3B e 3C; e localidade 9 - DF-3 - Figs. 2B, 2C e 4).

Falhas normais e inversas com diferentes geometrias foram descritas em todas as fácies deformacionais (e.g., DF-2 - localidade 10, Figs. 7D; e DF-3 - localidades 8, 9 e 12 , Figs. $8,10,5 B, 6 \mathrm{~A}$ e 6B). Contudo, a ocorrência smear de argila e ou areia contínuo ou descontínuo mostra alguma relação com as fácies. Bandas ou falhas com smear descontínuo de argila e/ou areia foram descritos em MTDs da fácies DF-2 com camadas caracterizadas 
por intercalação de laminações de areia e argila (e.g., localidade 10; Fig. 7D) ou por laminações de areia fina em areia média a grossa (e.g., localidade 1; Figs. 7A e 7B). Também ocorrem em blocos de ritmito (e.g., localidade 9; Fig. 6C e 7C), que mostram aspecto interno de deformação similar a DF-1 ou DF-2, e em resquícios de acamamento (e.g., localidade 9; Fig. 10) em matriz de MTDs da fácies DF-3. Já bandas ou falhas com smear contínuo de argila ocorrem na matriz de diamictitos da fácies DF-3 (e.g., localidades: 8 - Figs. 8, e 12 - Figs. 6A e 6B). Os boudins, por sua vez, foram identificados nas 3 fácies deformacionais com geometria simétrica (e.g., localidades: 11, DF-1; 13, DF-2, Fig. 9A; e 6, DF3, Fig. 9B) e nas fácies DF-2 (e.g., localidade 10, Fig. 9C) e DF-3 (e.g., localidade 8) com forma assimétrica.

A relação geral entre diversidade de estruturas e fácies deformacionais sugere uma influência do processo de evolução dos MTDs. A classificação dos MTDs em fácies deformacionais, proposta por Rodrigues et al. (2020), está baseada na quantidade de matriz nesses depósitos, onde DF-1 não apresenta matriz, DF-2 tem de menos de $5 \%$ até $50 \%$ e DF-3 mostra mais de $50 \%$ (Tabela 1). A matriz dos MTDs é considerada um produto do processo de desagregação e mistura dos sedimentos remobilizados por fluxo gravitacional em massa, o qual tende a resultar na homogeneização desses sedimentos (e.g., Strachan 2008, Rodrigues et al. 2020). O desenvolvimento de matriz estaria relacionado ao processo pelo qual movimentos em massa do tipo slides evoluem para slumps, e esses para debris flows (e.g., Nemec 1990, Martinsen 1994, Strachan 2008). Portanto, o processo de desagregação e mistura de sedimento durante o fluxo gravitacional parece promover a diversificação de estruturas de deformação, talvez associado ao aumento de variações reológicas, uma vez que esse processo tende a ocorrer de modo gradual e heterogêneo dentro do $M T D$ (e.g., Strachan 2008, Rodrigues et al. 2020).

A relação temporal entre as estruturas é muitas vezes incerta, porém dobras tendem a se formar anteriormente às falhas e boudins, uma vez que as dobras são por vezes deformadas por essas outras estruturas (Rodrigues et al. 2020). Esse tipo de relação entre dobras e falhas foi identificada em outros estudos e atribuída a uma fase principal de deformação tipo plástica ou dúctil seguida de uma fase tipo dúctil-rúptil a rúptil (e.g., Farrell 1984, Martinsen 1989, 1994, Martinsen \& Bakken 1990, Strachan \& Alsop 2006, Alsop \& Marco 2014, Ogata et al. 2014a, b). Por sua vez, essa mudança no estilo de deformação indica não apenas uma variação espacial, mas também temporal da reologia dentro do volume ressedimentado (e.g., Martinsen 1994, Alsop \& Marco 2014, Ogata et al. 2014a, b). Além do processo de desagregação e mistura dos sedimentos, a variação espacial e temporal da reologia também pode ser influenciada pelos processos de deformação (como dobramento, falhamento, boudinagem, entre outros) que podem promover, por exemplo, aumento na pressão de fluídos em camadas arenosas entre camadas argilosas (e.g., Strachan 2008, Rodrigues et al. 2020).
A liquefação, fluidificação e injeção de sedimentos sine pós-deposição do fluxo gravitacional têm sido descritas em diferentes estudos associada tanto a camadas parentais dentro do intervalo ressedimentado quanto aquelas sobre as quais os fluxos se desenvolvem e se depositam (e.g., Strachan 2002, 2008, Odonne et al. 2011, Ogata et al. 2012, 2014a, b, Sobiesiak et al. 2018). Os processos de liquefação, fluidificação e injeção de sedimentos são associados ao aumento na pressão de fluídos (Hurst et al. 2011). No caso dos MTDs do Grupo Itararé, a ocorrência de injetitos sin-fluxo também é um indicativo de mudanças de reologia em porções arenosas do depósito ou de camadas sotopostas associadas a mudança na pressão de fluídos durante o fluxo (Rodrigues et al. 2020). Injetitos gerados após a colocação do MTD podem estar relacionados ao aumento de pressão de fluídos de camadas ou clastos dentro ou sotopostos ao MTD, porém que somente foram capazes de intrudir com a diminuição da tensão na interrupção do fluxo, durante as fases de relaxamento e/ou compactação do depósito. Por sua vez, a injeção mútua de sedimentos que ocorre entre clastos intrabacinais e matriz de diamictito indica liquefação e fluidificação de sedimentos dentro do MTD durante seu transporte.

Contudo, com a evolução dos processos dentro dos fluxos gravitacionais em massa em direção à homogeneização dos sedimentos podemos esperar a destruição e obliteração de muitas estruturas. Aspectos de deformação das fácies DF-1 e DF-2 foram descritos por Rodrigues et al. (2020) restritas ao interior de seixos a grandes blocos intrabacinais dispersos na matriz da DF-3. Esses clastos são considerados prováveis remanescentes de fases iniciais de evolução do fluxo gravitacional (como slides/slumps) e, cujos sedimentos foram parcialmente incorporados pela matriz, como indicado pelas deformações observadas nas bordas desses clastos. Outra evidência dessa tendencia de destruição das estruturas é o cisalhamento progressivo de fragmentos e laminações observados na matriz de diamictitos. Apesar da diversidade de estruturas em um MTD mostrar alguma relação com a fácies deformacional, os diferentes estilos estruturais descritos neste artigo não estão diretamente relacionados a um tipo de fácies.

Variações na orientação e distribuição da tensão dentro de MTD podem resultar em regiões com diferentes estilos estruturais predominantes, que podem explicar em parte a diversidade de estilos estruturais. Em modelo simplificado, fluxos gravitacionais em massa se desenvolvem ao longo de uma zona de cisalhamento basal. Possuem domínio distensivo na parte proximal, compressivo na parte distal, zonas de deformação transcorrente (transpressiva e/ou transtrativa) nas margens e região central translacional caracterizada por predomínio de cisalhamento (e.g., Farrell 1984, Farrell \& Eaton 1987, Elliot \& Williams 1988, Webb \& Cooper 1988, Martinsen 1989, 1994, Martinsen \& Bakken 1990, Debacker et al. 2001, 2009, Strachan 2002, 2008, Alsop \& Marco 2014, Alsop et al. 2016, Cardona et al. 2020). Contudo, alguns estudos sugerem que a variedade de relações entre estruturas de distensão e compressão em um MTD resulta de células de fluxo de segunda ordem dentro do fluxo principal (primeira ordem) associadas a aceleração e/ou desaceleração dentro do fluxo em massa (Alsop \& Marco 2014). 

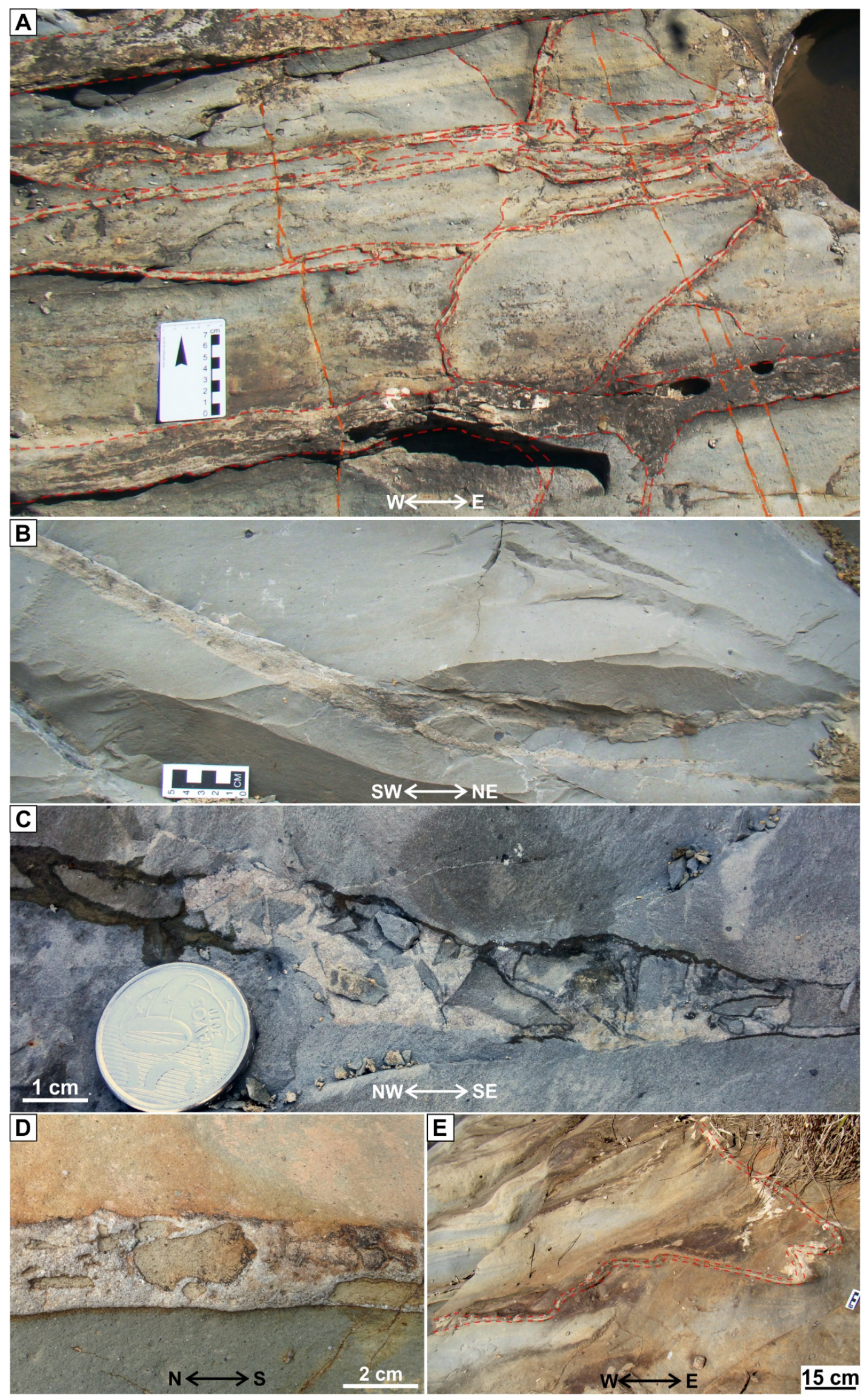

Figura 14 - Injetitos de areia em diamictitos: A) diques e soleiras de injeção de areia fina a grossa em diamictito com matriz bandada (localidade 1); B) injetito de areia fina a média em diamictito (localidade 8); C) e D) fragmentos incorporados das rochas hospedeiras pela injeção (localidades 8 e 1, respectivamente); e) soleira de injetito dobrada (localidade 1). 

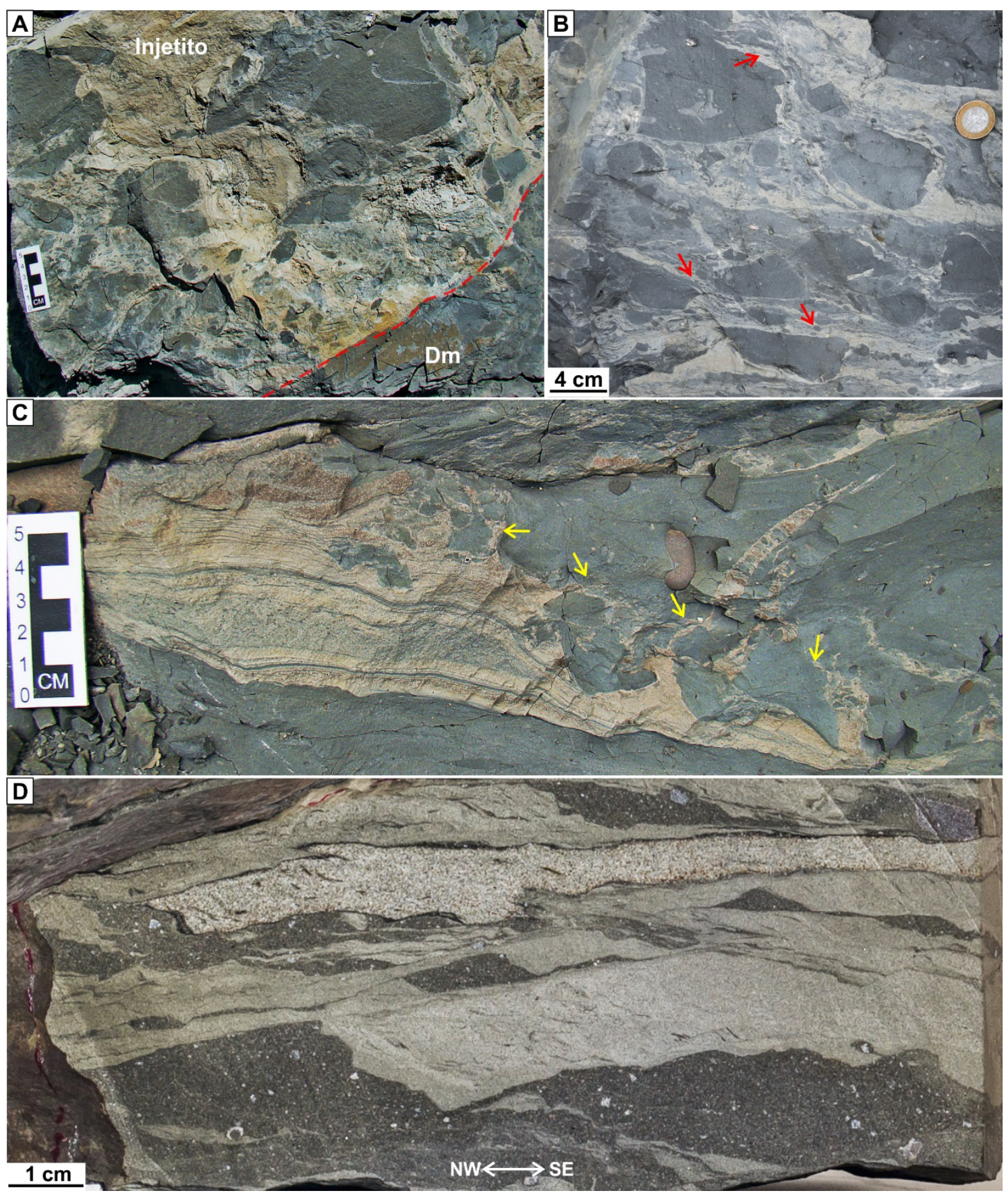

Figura 15 - A) e B) Injetitos de areia ricos em fragmentos de diamictito (Dm; rocha encaixante), os quais conferem aspecto brechado aos injetitos (blocos soltos do afloramento da localidade 7; A - adaptado de Rodrigues et al. 2020). Por vezes, esses injetitos mostram feições internas de fluxo com cisalhamento dos fragmentos da rocha encaixante (alguns exemplos indicados por setas vermelhas; B). C) Injeções de areia (principalmente na porção central e direita da fotografia) provenientes de resquício de camada arenosa fluidizada e injetada em diamictito, com porções da hospedeira englobados parcial a totalmente (alguns casos indicados por setas amarelas; bloco solto do afloramento da localidade 7). D) Injetito encaixado em ritmito; notar que a intrusão se espessa na mesma direção da cinemática das falhas no ritmito, o que sugere injeção sin-cisalhamento (amostra da localidade 10).

A região central dos MTDs tende ainda a mostrar variada combinação dos diferentes estilos (e.g., Martinsen 1989, 1994, Strachan 2008, Alsop \& Marco 2014, Alsop et al. 2016). Além disso, os fluxos em massa podem mostrar diferentes interações basais com o substrato podendo ser erodido e/ou deformado e incorporado ao fluxo (e.g., Frey-Martinez et al. 2006, Ogata et al. 2014a, b,
Valdez-Buso et al. 2019, Sobiesiak et al. 2018, Cardona et al. 2020). A variedade de estruturas e suas relações pode ainda estar relacionada a diferentes fases de evolução de um $M T D$, que corresponde a iniciação, translação, cessação, relaxamento e compactação (Farrell 1984, Strachan 2002, 2008, Alsop \& Marco 2011). 
Em geral, nos MTDs do Grupo Itararé foram descritas estruturas distensivas e compressivas num mesmo afloramento (e.g., localidade 13, Figs. 3D e 9A; localidade 9, Figs. 9D e 10), comumente, com similar proporção e, ocasionalmente, com relativo predomínio de um ou outro estilo (Rodrigues et al. 2020). Muitos dos afloramentos apresentam ainda uma ou mais estruturas do estilo cisalhante, que associadas a estruturas distensivas (e.g., localidade 10, Figs. 7D, 9C e 11A) e/ou compressivas (e.g., localidade 9, Figs. 9D, 10 e 12B), podem ser indicativas de porções mais proximais a centrais ou distais a centrais dos $M T D s$, respectivamente. A ocorrência de dobras deformadas por falhas normais sugere que esses MTDs podem ter registrado diferentes fases de evolução do fluxo em massa. Por sua vez, as estruturas associadas ao estilo de liquefação/fluidificação/ injeção parecem estar associadas a evolução da deformação dentro dos MTDs. Porém, a exposição limitada do Grupo Itararé tende a dificultar a identificação de regiões com estilos preferenciais de deformação dentro dos MTDs. Além disso, a relação temporal entre as estruturas tende a ser de difícil determinação, uma vez que relações de corte são incomuns.

Considerando o que foi apresentado, bem como outros registros da literatura (e.g., Vesely \& Assine 2006, Carvalho \& Vesely 2017, Valdez-Buso et al. 2019, Mottin et al. 2018, Schemiko et al. 2019, Rodrigues et al. 2020, entre outros), nem estilo estrutural, nem diversidade de estruturas ou mesmo um tipo de estrutura mostra distribuição geográfica ou estratigráfica preferencial. Mesmo dentro do MTC identificado na região de Aurora-Alfredo Wagner (Fig. 1) foram identificados os diversos estilos estruturais em diferentes posições dentro da seção estratigráfica (Fig. 1B). Poderíamos esperar um predomínio do estilo distensivo, translacional e compressivo nas porções proximal, mediana e distal, respectivamente, do MTC. Porém, o fato de MTCs serem formados por múltiplos MTDs implica que os diferentes domínios estruturais podem ocorrem em diferentes porções do MTC. Com relação às fácies deformacionais, diferentes regiões podem, aparentemente, mostrar menor ou maior variedade das fácies deformacionais como, por exemplo, as regiões de Campo do Tenente-Mafra e Witmarsum-Alfredo Wagner, respectivamente (Fig. 1). Contudo, isto parece resultar num maior ou menor grau de exposição dos afloramentos. $\mathrm{Na}$ região entre Campo do Tenente e Mafra, por exemplo, a maioria dos afloramentos com boa exposição consistem em pedreiras isoladas, enquanto na região entre Witmarsum e Alfredo Wagner os afloramentos estudados incluem cortes de estrada e pedreiras distribuídos de forma mais contínua, possibilitando que os MTDs sejam rastreados lateralmente. Todavia, a ocorrência de MTDs de uma ou mais fácies deformacionais dentro de um intervalo estratigráfico na mesma região deve ser avaliada, uma vez que pode indicar um aspecto da evolução dos depósitos naquela região e/ou um aspecto paleogeográfico (porções proximais ou distais do talude, por exemplo). No caso do $M T C$ identificado na porção sul da área de estudo (Rodrigues et al. 2020), verificamos que as fácies deformacionais tendem a mostrar distribuição pre- ferencial ao longo da seção (Fig. 1B), apesar dos estilos estruturais ou mesmo de estruturas específicas (e.g., dobras) não mostraram ocorrência preferencial. As fácies deformacionais aparecem distribuídas conforme sua evolução (aspecto de deformação e integridade das camadas remobilizadas) de $M T D s$ menos, moderadamente e mais deformados e homogeneizados (DF-1 - MTDs incipientes, DF-2 - MTDs maduros, e DF-3 MTDs evoluídos, respectivamente) de SE para NW na seção estratigráfica (Fig. 1). Considerando que a seção está orientada de modo aproximado à direção geral de fluxo (Rodrigues et al. 2021), o predomínio de fácies DF-1 na porção SE e de DF-3 na porção NW permite sugerir que essas porções da seção correspondem, respectivamente, as regiões proximal e distal do fluxo, corroborado pela distribuição de outros depósitos (como deltaicos e marinhos) ao longo da seção.

\section{Considerações finais}

$\mathrm{O}$ aprofundamento recente no estudo dos MTDs do Grupo Itararé, em relação tanto a sua evolução (Rodrigues et al. 2020) quanto sua associação com os demais depósitos (e.g., Suss et al. 2014, Fallgatter 2015, Carvalho \& Vesely 2017, Mottin et al. 2018, Schemiko et al. 2019), tem permitido avanços na compreensão da deposição de diferentes intervalos na Bacia do Paraná entre o Carbonífero e o Permiano. Resultados de estudos, por exemplo, na região de Rio do Sul (Santa Catarina), permitiram Schemiko et al. (2019) associar o desenvolvimento de fluxos gravitacionais a evolução de clinoformas progradacionais relacionadas a complexo deltaico. A caracterização da deformação nos MTDs juntamente com as interpretações deposicionais permitiram ainda sugerir a ocorrência de um complexo de transporte em massa (Fig. 1B), cuja seção mostra predomínio de fácies DF-1 e DF-2 (MTDs incipientes e maduros, respectivamente) a SE e de DF-2 e DF-3 (MTDs maduros e evoluídos, respectivamente) a NW, o que pode indicar porções mais proximais e distais do talude, respectivamente (Schemiko et al. 2019, Rodrigues et al. 2020). A análise estrutural e cinemática de estruturas de MTDs têm permitido ainda avanços na compreensão da paleogeografia da bacia em diferentes regiões, a partir da definição do paleofluxo dos MTDs e dos paleotaludes (e.g., Mottin et al. 2018, Rodrigues et al. 2021, Schemiko et al. 2019). Considerando as importantes implicações que os MTDs têm mostrado na compreensão da evolução deposicional do Grupo Itararé, a documentação e discussão sobre os diferentes estilos estruturais de tais depósitos poderá auxiliar estudos futuros.

Os MTDs do Grupo Itararé mostram uma diversidade de estilos estruturais e de estruturas de deformação compatíveis com o que vêm sendo descrito na literatura em outras bacias e outras idades. Essa diversidade pode estar relacionada a diferentes fatores e muitas vezes confere um aspecto estrutural complexo aos depósitos, principalmente quando estão parcialmente expostos. Apesar da exposição limitada do Grupo Itararé, observações de campo sugerem que fatores relacionados a diferentes fases de deformação, distribuição de estilos de deformação e mudanças reológicas podem explicar a diversidade de 
deformação observada. Outros fatores também podem ser considerados, tais como taxa de deformação, gradiente e morfologia do talude e fundo marinho, entre outros. Porém, a identificação tende a ser mais difícil com base em observações na escala de afloramento. Contudo, durante o estudo de um $M T D$, consideramos importante descrever as características do depósito (como composição, espessura etc.), suas estruturas (incluindo cinemática e relação temporal/espacial) e sua relação com os demais depósitos, assim como considerar possíveis fatores influenciadores, visando a compreensão da formação do depósito e de seu papel dentro da evolução da sucessão estratigráfica que o hospeda.

\section{Agradecimentos}

Os resultados aqui apresentados fazem parte de pesquisa de doutorado da primeira autora, realizada no Programa de Pós-graduação em Geologia da UFPR e com bolsa concedida pela Coordenação de Aperfeiçoamento de Pessoal em Nível Superior (CAPES). O trabalho teve o apoio financeiro do CNPq através do projeto "Depósitos de transporte em massa na sucessão neopaleozoica da Bacia do Paraná: estratigrafia, aspectos estruturais e significado tectônico" (processo 461650/2014-2). B.T. e F.F.V. agradecem ao CNPq pela concessão de bolsas de pesquisa (processos PQ 306780/2019-4 e PQ 303119/2020-9 respectivamente).

\section{Referências}

ALMEIDA F.F.M. 1948. A "Roche Moutonnée" de Salto, Estado de São Paulo. Boletim Geologia e Metalurgia, 5: 112-118.

ALSOP G.I., MARCO S. 2011. Soft-sediment deformation within seismogenic slumps of the Dead Sea Basin. Journal of Structural Geology, 33: 433-457.

ALSOP G.I., MARCO S. 2013. Seismogenic slump folds formed by gravity-driven tectonics down a negligible subaqueous slope. Tectonophysics 605, 48-69. https://doi.org/10.1016/j.tecto.2013.04.004

ALSOP G.I., MARCO S. 2014. Fold and fabric relationships in temporally and spatially evolving slump systems: A multi-cell flow model. Journal of Structural Geology 63, 27-49. https://doi.org/10.1016/j. jsg.2014.02.007

ALSOP G.I., MARCO S., WEINBERGER R., LEVI T. 2016. Sedimentary and structural controls on seismogenic slumping within mass transport deposits from the Dead Sea Basin. Sediment. Geol., 344: 71-90.

ARMITAGE D.A., ROMANS B.W., COVAULT J.A., GRAHAM S.A. 2009. The Influence of Mass-Transport-Deposit Surface Topography on the Evolution of Turbidite Architecture: The Sierra Contreras, Tres Pasos Formation (Cretaceous), Southern Chile. J. Sediment. Res. 79, 287-301. https://doi.org/10.2110/ jsr.2009.035

BERTON F., VESELY F.F. 2016. Stratigraphic evolution of Eocene clinoforms from northern Santos Basin, offshore Brazil: Evaluating controlling factors on shelf-margin growth and deep-water sedimentation. Marine and Petroleum Geology 78, 356-372.

BULL S., CARTWRIGHT J., HUUSE M. 2009. A review of kinematic indicators from mass-transport complexes using 3D seismic data. Mar. Pet. Geol. 26, 1132-1151. https://doi.org/10.1016/j.marpetgeo.2008.09.011

CALLOT P., SEMPERE T., ODONNE F., ROBERT E. 2008. Giant submarine collapse of a carbonate platform at the Turonian-Coniacian transition: the Ayabacas Formation, southern Peru. Basin Research 20, 333-357. https://doi.org/10.1111/ j.1365-2117.2008.00358.x
CANUTO J.R. 1985. Origem dos diamictitos e de rochas associadas do Subgrupo Itararé no sul do Estado do Paraná e norte de Santa Catarina. Dissertação de mestrado. Intituto de Geociências-USP.

CARDONA S., WOOD L.J., DUGAN B., JOBE Z., STRACHAN L.J. 2020. Characterization of the Rapanui mass-transport deposit and the basal shear zone: Mount Messenger Formation, Taranaki Basin, New Zealand. Sedimentology, 67: 2111-2148. https:// doi.org/10.1111/sed.12697

CARNEIRO C.D.R., COSTA F.G.D. 2006. Estruturas atectônicas da Bacia do Paraná em Campinas (SP): deformação sin-sedimentar no Subgrupo Itararé. Terrae Didática 2(1): p. 34-43.

CARVALHO A.H., VESELY F.F. 2017. Facies relationships recorded in a Late Paleozoic fluvio-deltaic system (Paraná Basin, Brazil): Insights into the timing and triggers of subaqueous sediment gravity flows. Sedimentary Geology, 352: 45-62.

CASTRO J.C. 1991. A evolução dos sistemas glacial, marinho e deltáico das formações Rio do Sul e Rio Bonito/Mb. Triunfo (Eopermiano), sudeste da Bacia do Paraná. Tese de Doutorado - Instituto de Geociências e Ciências Exatas da Universidade Estadual Paulista.

COSGROVE J.W. 2007. The use of shear zones and related structures as kinematic indicators: a review. In: Ries, A.C., Butler, R.W.H., Graham, R.H. (Eds.), Deformation of the Continental Crust: the Legacy of Mike Coward. Geological Society of London, Special Publication, vol. 272, pp. 59-74.

DASGUPTA P. 2003. Sediment gravity flow-the conceptual problems. Earth-Science Rev. 62, 265-281. https://doi.org/10.1016/S0012-8252(02)00160-5

D’ÁVILA R.S.F. 2009. Sequências Deposicionais do Grupo Itararé (Carbonífero e Eopermiano), Bacia do Paraná, na Área de Dr. Pedrinho e Cercanias, Santa Catarina, Brasil. Porto Alegre. Tese de Doutorarado - Universidade do Vale do Rio dos Sinos - UNISINOS, 192p. 
DE BLASIO F.V., ELVERHØI A. 2010. Properties of mass-transport deposits as inferred from dynamic modeling of subaqueous mass wasting: a short review. Mass-Transport Deposits in Deepwater Settings SEPM Special Publication SEPM (Society for Sedimentary Geology), 10p.

DEBACKER T.N., DUMON M., MATTHYS A. 2009. Interpreting fold and fault geometries from within the lateral to oblique parts of slumps: a case study from the Anglo-Brabant Deformation Belt (Belgium). Journal of Structural Geology, 31: 1525-1539.

DEBACKER T.N., SINTUBIN M., VERNIERS J. 2001. Large-scale slumping deduced from structural and sedimentary features in the Lower Palaeozoic Anglo-Brabant fold belt, Belgium. J. Geol. Soc. of London 158, 341-352. https://doi.org/10.1144/jgs.158.2.341

DERBY O.A. 1878. A geologia da região diamantífera da Província do Paraná. Arquivos do Museu Nacional, 3:89-96.

DYKSTRA M., GARYFALOU K., KERTZNUS V., KNELLER B., MILANA J.P., MOLINARO M., SZUMAN M., THOMPSON P. 2011. Mass-transport deposits: combining outcrop studies and seismic forward modeling to understand lithofacies distributions, deformation, and their seismic expression. In: Shipp C., Weimer P. and Posamentier H. (Eds.) Mass-Transport Deposits. SEPM, Tulsa, OK.

ELLIOT C.G., WILLIAMS P.F. 1988. Sediment slump structures: a review of diagnostic criteria and application to an example from Newfoundland. Journal of Structural Geology 10, 171-182.

EYLES C.H., EYLES N., FRANCA A.B. 1993 Glaciation and tectonics in an active intracratonic basin: the late Palaeozoic Itarare Group, Parana Basin, Brazil. Sedimentology 40, 1-25.

FARRELL S.G. 1984. A dislocation model applied to slump structures: Journal of Structural Geology, 6: 727-736.

FARRELL S.G., EATON S. 1987. Slump strain in the Tertiary of Cyprus and the Spanish Pyrenees. Definition of palaeoslopes and models of soft sediment deformation. In: Jones M.F., Preston R.M.F. (Eds.), Deformation of Sediments and Sedimentary Rocks, Special Publication of the Geological Society of London, 29: 181-196.

FISHER Q.J., KNIPE R.J. 2001. The permeability of faults within siliciclastic petroleum reservoirs of the North Sea and Norwegian Continental Shelf. Mar. Pet. Geol., 18: 1063-1081.

FLEUTY M. J. 1964. The description of folds. Proc. Geol. Assoc., 75, 461-492.

FOSSEN H. 2016. Structural geology. Cambridge University Press, $2^{\text {nd }}$ edition, $510 \mathrm{p}$.
FRANÇA A.B., POTTER P.E. 1988. Estratigrafia, ambiente deposicional e análise de reservatório do Grupo Itararé (Permocarbonífero), Bacia do Paraná (parte 1). Boletim de Geociências da Petrobrás, 2, 147-191.

FRANÇA A.B., POTTER P.E. 1991. Stratigraphy and reservoir potential of glacial deposits of the Itararé Group (Carboniferous-Permian), Paraná Basin, Brazil. AAPG Bulletin, 75: 62-85.

FREY-MARTINEZ J., CARTWRIGHT J., JAMES D. 2006. Frontally confined versus frontally emergent submarine landslides: a 3D seismic characterisation. Mar. Petrol. Geol. 23, 585-604. https://doi.org/10.1016/j.marpetgeo.2006.04.002

GAMA JR. E. G., PERINOTTO J. A. J., RIBEIRO H. J. P. S., PADULA E. K. 1992. Contribuição ao estudo da ressedimentação no Grupo Itararé: tratos de fácies e hidrodinâmica deposicional. Revista Brasileira de Geociências, 22: 228-236.

GORDON M.J. 1947. Classificação das formações gondwânicas do Paraná, Sante Catarina e Rio Grande do Sul. Notas Preliminares e Estudos da Divisão de Geologia e Mineralogia do DNPM, 38: 1-20.

GOSCOMBE B.D., PASSCHIER C.W., HAND M. 2004. Boudinage classification: End-member boudin types and modified boudin structures. Journal of Structural Geology 26, 739-763. https://doi.org/10.1016/j. jsg.2003.08.015

HANSEN E. 1971. Strain Facies. Springer-Verlag, Berlin, $207 p$.

HURST A., SCOTT A., VIGORITO M. 2011. Physical characteristics of sand injectites. Earth-Science Reviews, 106 (3-4), 215-246. https://doi.org/10.1016/j. earscirev.2011.02.004

JABLONSKA D., DI CELMA C.N., ALSOP G.I., TONDI E. 2018. Internal architecture of mass-transport deposits in basinal carbonates: A case study from southern Italy. Sedimentology 65, 1246-1276. https:// doi.org/10.1111/sed.12420

JENNER K.A., PIPER D.J.W., CAMPBELL D.C., MOSHER D.C. 2007. Lithofacies and origin of late Quaternary mass transport deposits in submarine canyons, central Scotian Slope, Canada: Sedimentology, 54: 19-38.

JONES O.T. 1939. The geology of the Colwyn Bay district: A study of submarine slumping during the Salopian period: Geological Society of London Quarterly Journal, 95: 335-382.

KRISTENSEN M.B., CHILDS C., OLESEN N.Ø., KORSTGÅRD J.A. 2013. The microstructure and internal architecture of shear bands in sand-clay sequences. Journal of Structural Geology, 46: 129-141.

LEINZ V. 1937. Estudos sobre a glaciação carbonífera no sul do Brasil. Boletim DNPM/DFPM, 21: 1-47. 
LUCENTE C.C., PINI G.A. 2003. Anatomy and emplacement mechanism of a large submarine slide within a Miocene foredeep in the northern Apennines, Italy: a field perspective. American Journal of Science 303, 565-602.

MARTIN H. 1961. The directions of flow of the Itararé ice sheets in the Paraná Basin, Brazil. Boletim Paranaense de Geografia, 10/15: 25-77.

MARTINSEN O. J., BAKKEN B. 1990. Extensional and compressional zones in slumps and slides in the Namurian of County Clare, Ireland. Journal Geological Society of London, 147: 153-164.

MARTINSEN O.J. 1989. Styles of soft-sediment deformation on a Namurian delta slope, Western Irish Namurian Basin, Ireland. In: WHATELEY M.K.G., PICKERING K. T. (Eds.), Deltas: sites and traps for fossil fuels. Special Publication Geological Society London, 1: 167-177.

MARTINSEN O.J. 1994. Mass movements, in MALTMAN A., ed., The Geological Deformation of Sediments: London, Chapman \& Hall, 127-165p.

MOSCARDELLI L., WOOD L., MANN P. 2006. Mass-transport complexes and associated processes in the offshore area of Trinidad and Venezuela. Am. Assoc. Pet. Geol. Bull. 90, 1059-1088. https://doi. org/10.1306/02210605052

MOSCARDELLI, L., WOOD, L. 2016. Morphometry of mass transport deposits as a predictive tool. Geol. Soc. Am. Bull., 128, 47-80. https://doi.org/10.1130/B31221.1

MOTTIN T.E., VESELY F.F., DE LIMA RODRIGUES M.C.N., KIPPER F., DE SOUZA P.A. 2018. The paths and timing of late Paleozoic ice revisited: New stratigraphic and paleo-ice flow interpretations from a glacial succession in the upper Itararé Group (Paraná Basin, Brazil). Palaeogeography, Palaeoclimatology, Palaeoecology 490, 488-504. https://doi.org/10.1016/j.palaeo.2017.11.031

NARDIN T.R., HEIN F.J., GORSLINE D.S., EDWARDS B.D. 1979. A review of mass movement processes, sediment and acoustic characteristics and contrasts in slope and base-of-slope systems versus canyon-fan-basin-floor basins. In: DOYLE L.J., PILKEY O.H., eds., Geology of continental slopes: Society of Economic Paleontologists and Mineralogists Special Publication, 27: 61-73.

NEMEC W. 1990. Aspects of sediments movements on steep delta slopes. In: COLELLA A., PRIOR D. B. (ed.) Coarse-Grained Deltas. International Association of Sedimentologists, Special Publication 10: 29-73.

ODONNE F., CALLOT P., DEBROAS E.J., SEMPERE T., HOAREAU G., MAILLARD A. 2011. Soft-sediment deformation from submarine sliding: Favourable conditions and triggering mechanisms in examples from the Eocene Sobrarbe delta (Ainsa, Spanish Pyrenees) and the mid-Cretaceous Ayabacas Formation (Andes of Peru). Sediment. Geol. 235, 234-248. https://doi.org/10.1016/j.sedgeo.2010.09.013
OGATA K., MUTTI E., PINI G.A., TINTERRI R. 2012. Mass transport-related stratal disruption within sedimentary mélanges: Examples from the northern Apennines (Italy) and south-central Pyrenees (Spain). Tectonophysics 568-569, 185-199,. https://doi.org/10.1016/j.tecto.2011.08.021

OGATA K., MOUNTJOY J.J., PINI G.A., FESTA A., TINTERRI R. 2014a. Shear zone liquefaction in mass transport deposit emplacement: A multi-scale integration of seismic reflection and outcrop data. Marine Geology 356, 50-64. https://doi.org/10.1016/j.margeo.2014.05.001

OGATA K., PINI G.A., FESTA A., POGACNIK Z., TUNIS G. 2014b. High-Resolution Studies of Mass Transport Deposits: Outcrop Perspective for Understanding Modern Submarine Slope Failure and Associated Natural Hazards. In: Lollino G., Manconi A., Locat J., Huang Y., Canals Artigas M. (eds) Engineering Geology for Society and Territory Volume 4. Springer, Cham. https://doi.org/10.1007/978-3-31908660-6_40

OGATA K., POGAČNIK Ž., PINI G.A., TUNIS G., FESTA A., CAMERLENGHI A., REBESCO M. 2014c. The carbonate mass transport deposits of the Paleogene Friuli Basin (Italy/Slovenia): Internal anatomy and inferred genetic processes, Marine Geology 356, 88110. https://doi.org/10.1016/j.margeo.2014.06.014.

OGATA K., PINI G.A., FESTA A., POGAČNIK Ž., LUCENTE C.C. 2016. Meso-Scale Kinematic Indicators in Exhumed Mass Transport Deposits: Definitions and Implications. In: Lamarche G. et al. (eds) Submarine Mass Movements and their Consequences. Advances in Natural and Technological Hazards Research, vol 41. Springer, Cham. https://doi.org/10.1007/978-3319-20979-1_46

OLIVEIRA E.P. 1916. Geologia do Estado do Paraná. Boletim do Ministério da Agricultura, Indústria e Comércio, 5:67-143.

OLIVEIRA E.P. 1927. Geologia e recursos minerais do Estado do Paraná. Monografia do Serviço Geológico e Mineiro do Brasil, 6:1-169.

POSAMENTIER H.W., KOLLA V. 2003. Seismic geomorphology and stratigraphy of depositional elements in deep-water settings: Journal of Sedimentary Research, 73: 367-388.

POSAMENTIER H.W., MARTINSEN O.J. 2011. The character and genesis of submarine mass-transport deposits: insights from outcrop and 3D seismic data, Mass-Transport Deposits in Deepwater Settings.

POSAMENTIER H.W., WALKER R.G. 2006. Deep-water turbidites and submarine fans. In: POSAMENTIER H.W., WALKER R.G., eds., Facies Models Revisited: SEPM, Special Publication, 84: 397-520.

PRIOR D.B., COLEMAN J.M. 1978. Disintegrating retrogressive landslides on very low-angle subaqueous slopes, Mississippi delta. Marine Geotechnology, 3: 37-60. 
ROCHA-CAMPOS, A.C. 1963. Deformação penecontemporânea em sedimentos glacio-lacustres do Grupo Tubarão. Boletim da Sociedade Brasileira de Geologia, 12: 49-56.

RODRIGUES M. C. N. L., FOLMANN M., TRZASKOS B., VESELY F.F. 2015. Registro estrutural de depósitos de transporte em massa do Permiano Inferior da Bacia do Paraná. In: XV Simpósio Nacional de Estudos Tectônicos, Vitória, Anais.

RODRIGUES M.C.N.L., TRZASKOS B, ALSOP G. I., VESELY F.F., MOTTIN T.E., SCHEMIKO D.C.B. 2021. Statistical analysis of structures commonly used to determine palaeoslopes from within mass transport deposits, Journal of Structural Geology 151, 104421. https://doi.org/10.1016/j.jsg.2021.104421.

RODRIGUES M. C. N. L., TRZASKOS B., ALSOP G. I., VESELY F.F. 2020. Making a homogenite: An outcrop perspective into the evolution of deformation within mass-transport deposits. Mar. Petrol. Geol., 112 104033. https://doi.org/10.1016/j.marpetgeo.2019.104033

ROSTIROLLA S.P., MANCINI F., RIGOTI A., KRAFT R.P. 2003. Structural styles of the intracratonic reactivation of the Perimbó fault zone, Paraná basin, Brazil. J. South Am. Earth Sci. 16, 287-300. https://doi. org/10.1016/S0895-9811(03)00065-8

SALAMUNI R., MARQUES FILHO P.L., SOBANSKI A.C. 1966. Considerações sobre turbiditos da Formação Itararé (Carbonífero Superior), Rio Negro-PR e Mafra-SC. Boletim da Sociedade Brasileira de Geologia, 15: 1-19.

SANFORD R.M., LANGE F.W. 1960. Basin study approach to oil evaluation of Paraná miogeosincline, South Brasil. Bulletin of American Association of Petroleum Geologists, 44(8): 1316-1370.

SCHEMIKO D.C.B., VESELY F.F., RODRIGUES M.C.N.L. 2019. Deepwater to fluvio-deltaic stratigraphic evolution of a deglaciated depocenter: The early Permian Rio do Sul and Rio Bonito formations, southern Brazil. J. South Amer. Earth Sci. 95, 102260 https://doi.org/10.1016/j.jsames.2019.102260

SCHNEIDER R. L., MUHLMANN H., TOMMASI E., MEDEIROS R.A., DAEMON R.A., NOGUEIRA A.A., 1974. Revisão estratigráfica da Bacia do Paraná. In: SBG, 28 Congresso Brasileiro de Geologia, Porto Alegre, 1: 41-65.

SOBIESIAK M.S., KNELLER B., ALSOP G.I., MILANA J.P. 2016. Internal deformation and kinematic indicators within a tripartite mass transport deposit, NW Argentina. Sediment. Geol. 344, 364-381. https://doi.org/10.1016/j.sedgeo.2016.04.006.

SOBIESIAK M.S., KNELLER B., ALSOP G.I., MILANA J.P. 2018. Styles of basal interaction beneath mass transport deposits. Mar. Pet. Geol. 98. https:// doi.org/10.1016/j.marpetgeo.2018.08.028
SOUZA P.A. 2006. Late carboniferous palynostratigraphy of the itarare subgroup, northeastern Paraná Basin, Brazil. Rev. Palaeobot. Palynol., 138, 9-2.

SOUZA P.A., MARQUES-TOIGO M. 2003. An overview on the palynostratigraphy of the Upper Paleozoic strata of the Brazilian Paraná Basin. In: Rev. Mus. Arg. Cienc. Nat. 5. pp. 205-214.

STRACHAN L.J. 2002. Slump-initiated and controlled syndepositional sandstone remobilization, an example from the Namurian of County Clare, Ireland. Sedimentology, 49: 25-41.

STRACHAN L.J. 2008. Flow transformations in slumps: a case study from the Waitemata Basin, New Zealand. Sedimentology, 55: 1311-1332.

STRACHAN L.J., ALSOP G.I. 2006. Slump folds as indicators of paleoslope: a case study from the Fisherstreet Slump of County Clare, Ireland: Basin Research, 18: 451-470.

SUSS J.F., VESELY F.F., SANTA CATHARINA A., ASSINE M. L., PAIM P.S.G. 2014. O Grupo Itararé (Neocarbonífero-Eopermiano) entre Porto Amazonas (PR) e Mafra (SC): sedimentação gravitacional em contexto marinho deltaico com influência glacial. São Paulo, UNESP, Geociências, 33(4): 701-719.

TRZASKOS B., VESELY F.P., ROSTIROLLA S.P. 2006. Eventos tectônicos recurrentes impressos no arcabouço estratigráfico do Grupo Itararé na região de Vila Velha, Estado do Paraná. Bol. Parana. Geosci., 89-104.

VALDEZ-BUSO, V., AQUINO, C.D., PAIM, P.S.G., DE SOUZA, P.A., MORI, A.L., FALLGATTER, C., MILANA, J.P., KNELLER, B. 2019. Late Palaeozoic glacial cycles and subcycles in western Gondwana: Correlation of surface and subsurface data of the Paraná Basin, Brazil. Palaeogeography, Palaeoclimatology, Palaeoecology. https://doi.org/10.1016/j.palaeo. 2017.09.004

VESELY F.F., ASSINE M.L. 2004. Sequencias e tratos de sistemas deposicionais do Grupo Itararé, norte do Estado do Paraná. Revista Brasileira de Geociências, 34: 219-230.

VESELY F.F., ASSINE M.L. 2006. Deglaciation sequences in the Permo-Carboniferous Itararé Group, Paraná Basin, southern Brazil. Journal of South American Earth Sciences, Oxford, 22(3-4): 156-168.

VESELY F.F., ASSINE M.L., ROSTIROLLA S.P. 2005. Deformação penecontemporânea no Grupo Itararé, Bacia do Paraná: estilos estruturais, dinâmica sedimentar e implicações paleogeográficas. In: Simpósio Nacional de Estudos Tectônicos, 10, Curitiba, Anais. Curitiba: SBG núcleo PR. (CD-ROM).

VESELY F.F., RODRIGUES M.C.N.L., DA ROSA E.L.M., AMATO J.A., TRZASKOS B., ISBELL J.L., FEDORCHUK N.D. 2018. Recurrent emplacement of non-glacial diamictite during the late Paleozoic ice age. Geology, 46(7), 615-618. https://doi. org/10.1130/G45011.1 
WALDRON J.W.F., GAGNON J.F. 2011. Recognizing soft-sediment structures in deformed rocks of orogens. J. Struct. Geol. 33, 271-279. https://doi.or$\mathrm{g} / 10.1016 / \mathrm{j}$.jsg.2010.06.015

WEBB B. C., COOPER A. H. 1988. Slump folds and gravity slide structures in a Lower Palaeozoic marginal basin sequence (the Skiddaw Group), NW England. Journal of Structural Geology, Vol. 1 (5), 463-472.
WHITE I.C. 1908. Relatório sobre as Coal Measures e rochas associadas no sul do Brasil. Comissão de Estudos das Minas de Carvão de Pedra, Rio de Janeiro, Relatório Final.

WOODCOCK, N.H. 1979. The use of slump structures as paleoslope orientation estimators: Sedimentology, 26: 83-99. 